\title{
Can Investor Sentiment Be a Momentum Time-Series Predictor? Evidence from China
}

\author{
Xing $\mathrm{Han}^{\mathrm{a}, \mathrm{b}, *}$, Youwei $\mathrm{Li}^{\mathrm{c}}$ \\ ${ }^{a}$ Department of Accountancy and Finance, University of Otago, 60 Clyde Street, 9016 Dunedin, NZ \\ ${ }^{\mathrm{b}}$ Department of Financial Economics, Ghent University, Sint-Pietersplein 5, 9000 Ghent, Belgium \\ ${ }^{\mathrm{c}}$ School of Management, Queen's University Belfast, 185 Stranmillis Road, BT9 5EE Belfast, UK
}

First version: 20 Apr. $2015 \quad$ This version: 12 Jan. 2017

\begin{abstract}
This paper challenges the prevailing view that investor sentiment is a contrarian predictor of market returns at nearly all horizons. As an important piece of "out-of-sample" evidence, we document that investor sentiment in China is a reliable momentum signal at monthly frequency. The strong momentum predictability is robust under both single- and multi-regressor settings, and is statistically and economically significant both in and out of sample, enhancing portfolio performance as shown by our numerical examples. More importantly, we find a striking term structure that local sentiment shifts from a short-term momentum predictor to a contrarian predictor in the long run. Cross-sectional analysis reveals that sentiment is more of a small-firm effect. Finally, we confirm that global sentiment spills over to the local Chinese market, as it predicts negatively future returns over the longer horizons and in the cross section.
\end{abstract}

\section{JEL classification: C22; C53; G11; G12; G17}

\section{Keywords: Investor Sentiment; Return Predictability; Bias Correction; China}

\footnotetext{
* Corresponding Author: Department of Accountancy and Finance, University of Otago, 60 Clyde Street, Dunedin 9016, New Zealand. Tel.: +64-(0)3 479 9066. Fax: +64 (0)3 479 8171. E-mail: xing.han@ otago.ac.nz (X. Han).

The authors are grateful to an anonymous referee, Péter Erdős, Gerdie Everaert, Michael Frömmel, Xuezhong He, Kai Li, Alexander Mende, Dagfinn Rime, Lei Shi, Joris Wauters, and seminar participants at the 2015 annual conference of the European Economics and Finance Society (Brussels), the 2015 joint conference on Institutional Investors and Emerging Market Finance (Ghent), the 2016 annual conference of the Royal Economics Society (Brighton), the 2016 Spring Meeting of Young Economists (Lisbon), the 2016 workshop on Asia and Pacific Economies by Xi'an Jiaotong-Liverpool University \& Asian Development Bank Institute (Suzhou), the 2016 FMA annual conference (Las Vegas), the 2016 Auckland Finance Meeting (Auckland), the Inaugural Workshop on the Complex Information \& Financial Market Dynamics by Tianjin University (Tianjin), IÉSEG School of Management (Lille), University of Technology Sydney (Sydney), and ShanghaiTech University (Shanghai) for their detailed comments and suggestions. Han gratefully acknowledges Mengna Zhu and the research department of China International Capital Corporation Limited for sharing the data and the Fonds Wetenschappelijk Onderzoek (FWO Research Fund - Flanders) for financial support. Li acknowledges the support of National Natural Science Foundation of China (No. 71571197). All remaining errors are ours.
} 


\title{
Can Investor Sentiment Be a Momentum Time-Series Predictor? Evidence from China
}

\begin{abstract}
This paper challenges the prevailing view that investor sentiment is a contrarian predictor of market returns at nearly all horizons. As an important piece of "out-of-sample" evidence, we document that investor sentiment in China is a reliable momentum signal at monthly frequency. The strong momentum predictability is robust under both single- and multi-regressor settings, and is statistically and economically significant both in and out of sample, enhancing portfolio performance as shown by our numerical examples. More importantly, we find a striking term structure that local sentiment shifts from a short-term momentum predictor to a contrarian predictor in the long run. Cross-sectional analysis reveals that sentiment is more of a small-firm effect. Finally, we confirm that global sentiment spills over to the local Chinese market, as it predicts negatively future returns over the longer horizons and in the cross section.
\end{abstract}

JEL classification: C22; C53; G11; G12; G17

Keywords: Investor Sentiment; Return Predictability; Bias Correction; China 
"Studies of the sentiment of investors are important for two reasons. First, they teach us about biases in the stock market forecasts of investors. Second, they teach us about opportunities to earn extra returns by exploiting those biases."

—Kenneth L. Fisher and Meir Statman (2000)

\section{Introduction}

The effect of investor sentiment on asset prices has long been a debatable issue in financial economics. On the theoretical side, proponents of the efficient market hypothesis (EMH) argue that the impact of sentiment is "at most" negligible, as rational investors ruthlessly arbitrage away any sentiment-induced mispricing. Theorists from the behavioral camp, however, contend that sentiment induces systematic deviations from fundamental values due to the well-known "limit to arbitrage" argument (De Long et al. 1990a). Besides, Brown and Cliff (2005) and Baker and Wurgler (2006) point out that sentiment tends to have a long-lasting effect, so that the demand shocks of uninformed investors (e.g. noise traders) may be correlated over time to give rise to strong and persistent mispricing. Intuitively, the impact of sentiment on returns should be stronger for markets with binding arbitrage constraints (Kling \& Gao 2008) or that are more culturally collectivistic and highly prone to herding (Schmeling 2009). Still, whether investor sentiment matters for asset returns is an empirical issue.

This article relates to the above classical, yet contestable topic by investigating thoroughly the return predictability of investor sentiment over multiple horizons in China, the largest and most liquid emerging stock market. Prior works on the predictive power of sentiment mainly focused on US and other developed markets (Brown \& Cliff 2004, 2005; Baker \& Wurgler 2006, 2007; Huang et al. 2014), and uniformly find that sentiment is a strong long-term contrarian predictor (Baker \& Stein 2004; Brown \& Cliff 2005; Baker et al. 2012). ${ }^{1}$ High sentiment is linked with low market returns in the long run, implying (possible) market revision over time. Moreover, the contrarian predictability is more pronounced in the cross section (Baker \& Wurgler 2006; Baker et al. 2012). Baker and Wurgler (2007) attribute the contrarian predictability to the mean-

\footnotetext{
${ }^{1}$ It should be noted that the strikingly large long-run predictability documented in the empirical literature is not without controversy. See Boudoukh et al. (2008) for the caveats in long-horizon regressions.
} 
reverting pattern in sentiment. That is, sentiment wanes in the long run and market corrects the mispricing induced by sentiment.

Unfortunately, the empirical evidence on near-term return predictability, compared with the strong long-term predictability, is both thin and unclear. Using a wide range of sentiment proxies, including technical indicators and survey type data, Brown and Cliff (2004) find little, if any, evidence that sentiment forecasts returns at the weekly and monthly frequency in the US. Huang et al. (2014), however, find some statistical evidence that investor sentiment forecasts negatively future monthly returns with the aligned sentiment index, but not with the Baker and Wurgler (2006) sentiment index, which is more commonly used in empirical studies.

The somewhat ambiguous empirical evidence on the short-term return predictability of investor sentiment motivates our study, as the widely perceived contrarian predictability of investor sentiment in the long run does not necessarily carry over to the short run. Moreover, compared with developed markets, emerging markets tend to have binding arbitrage constraints, pervasive local retail investors, and less openness to international (institutional) investors. Therefore, whether we could find a similar contrarian predictability pattern in alternative market settings remains an interesting, yet unanswered question. The Chinese stock market provides a natural experiment for such an "out-of-sample" test in the spirit of Lo and MacKinlay (1990). It is wellknown for its distinctive features from the US and other developed market. First, it is generally regarded as a highly speculative market dominated by the trading of individual investors. Individual investors (noise traders) have more market power in China than in developed markets. Second, it is highly restrictive because of its stringent institutional settings such as strong shortsales constraints. The high short-selling costs also hinder institutional investors (rational investors) to engage in price stabilizing activities by trading against noise traders in China. All of these unique features, which are different from the US market (and other major developed markets), seem to tilt more towards the possibility that irrational sentiment leads to the expectation of increased future returns in the short term.

It should be noted that a number of prior works have shed some light on the sentiment impact on China's stock market. For example, Chi et al. (2012) use mutual fund flow as a sentiment proxy and find that high sentiment stocks earn high average returns compared with low sentiment stocks between 2004 and 2008. Kling and Gao (2008), however, document that a survey-based 
institutional investor sentiment measure offers no return predictability at the daily frequency. Chen et al. (2014) construct a market-based Chinese sentiment index and find their sentiment index has good forecasting power for the market movements. However, their sentiment index contains both rational and irrational components, which makes it difficult to interpret the sources of the forecasting power. Alongside these prior works, our article contributes to the evolving literature on sentiment in a number of distinctive ways:

First, we motivate a thorough discussion on the possible mechanisms through which the sentiment of investors might impact on subsequent returns. In particular, we emphasize the competing hypotheses regarding the short-run return predictability of sentiment. For emerging markets with pervasive irrational speculation (e.g. positive feedback trading) and binding arbitrage constraints (e.g. stronger short-sales constraints and less openness to international investors), the level of investor sentiment is very likely to forecast positively stock returns in the short run, while still predicting negatively the stock returns over longer horizons. Obviously, our perceived view challenges the conventional view that investor sentiment is a contrarian predictor at nearly all horizons, which is drawn almost exclusively from the evidence in the US and other developed markets.

Second, we piece together a number of imperfect sentiment proxies and extract their common component to form a real-time market-based sentiment index, which spans a period of 17 years (1997-2013). Obviously, the much longer and more recent sample period guarantees that our analysis on the possible effect on China's stock market is the most comprehensive and the most up-to-date. For example, Chi et al. (2012) use a sample which covers only from 2004 to 2008. The much larger sample size, compared with the prior studies, will undoubtedly increase the statistical power for the time-series regressions employed in the article.

Third, we properly address the Stambaugh (1999) estimation bias inherent in the predictive regression with a persistent predicting variable, while this important econometric issue has often been overlooked in prior works such as in Chi et al. (2012). Our simulation evidence reveals that the ordinary least square (OLS) slope coefficient on sentiment tends to be downward biased towards the (spurious) finding of contrarian predictability. Therefore, we employ a number of refined econometric techniques, including bias-reduction in coefficients and wild bootstrap for test statistics, to provide compelling evidence that investor sentiment is indeed a reliable 
momentum predictor for subsequent monthly market returns in China, confirming the momentum hypothesis. A one-standard-deviation increase in sentiment translates into a $1.50 \%$ rise in the equity premium per month, an economically significant result for all market participants. The strong positive return predictability is robust under both single-and multi-regressor settings, and is statistically and economically significant both in and out of sample.

Fourth, the strong out-of-sample predictability at monthly frequency renders us to construct profitable investment strategies based on the strong forecasting power of investment sentiment. Our numerical example suggests that our sentiment-based signals enhance the portfolio performance, and outperform the naïve buy-and-hold portfolio. More importantly, the investor reaps much higher rewards on a risk adjusted basis, if he or she follows the trading signals generated by sentiment rather than past returns.

Fifth, we investigate the term structure of the return predictability of investor sentiment in China. Evidence from multi-horizon predictive regressions yields a striking term pattern: Investor sentiment converts from a momentum predictor in the short run (e.g. within the first year) to a contrarian predictor in the subsequent, longer horizons (from two to five years). The fact that sentiment forecasts negatively market returns in the long run confirms the well-known contrarian predictability of sentiment, as the sentiment mean reverts over an unknowingly long horizon. We also examine the potential spillover effect of global sentiment on China's stock market. In contrast to local sentiment, we find global sentiment does not have an immediate impact, but predicts returns negatively over much longer horizons.

Last, but not least, we perform a batch of cross-sectional analyses. Using size-sorted portfolios as proxies for stocks with different sentiment sensitivity, we find that local investor sentiment is more of a size story (Lee et al. 1991): The short-term momentum pattern of sentiment matters more for small-cap stocks than for large-cap ones. In contrast, there seems less cross-sectional difference for the impact of global sentiment, as it uniformly predicts negatively long-run stock returns across the size groups.

The structure of the paper is as follows. Section 2 first introduces the Chinese stock market and then reviews the relevant literature and puts forth the competing testable hypotheses. Section 3 describes the data sources, the construction of sentiment index, and descriptive statistics. Section 
4 provides the main results of the return predictability over various horizons. Section 5 performs cross-sectional analyses. Section 6 discusses the implications of our findings and concludes.

\section{Literature Review}

\subsection{The Introduction of the Chinese Stock Market}

There are two major security exchanges in mainland China: the Shanghai Stock Exchange (SHSZ) and the Shenzhen Stock Exchange (SZSE). The two exchanges have no functional difference, except that SHSZ is larger than SZSE in terms of market capitalization. At the end of 2013, both exchanges are ranked among the top 12 stock exchanges in the world based on the total value of market capitalization (see Table A.2 in the appendix). The combined market capitalization of SHSZ and SZSE is equivalent to $42 \%$ of China's GDP in 2013. For historical reasons, common shares in the two exchanges are classified as A-shares and B-shares, which are denominated in local currency and foreign currencies (USD or Hong Kong dollar), respectively. As A-shares comprise the lion's share (96\%) of the market, we focus exclusively on the A-share market for our empirical analyses.

Several distinctive features regarding the Chinese A-share market are worth mentioning:

First and foremost, the Chinese market is well known for its speculative nature with a huge amount of young and inexperienced retail investors. According to the 2013 annual report of China Securities Depository and Clearing Corporation, there are more than 53 million valid individual investor accounts in SHSE and SZSE, among which $44 \%$ of the account holders are less than 40 years old. Less than $20 \%$ of the retail investors have an education background of bachelor degree or above. A breakdown on the stock holdings and trading activities in SHSE (Panel B of Table A.2) provides more insights: Individual investors hold directly more than $21 \%$ of the total market capitalization of the stocks in SHSZ. In comparison, stock holdings by professional institutions-including investment funds, pension funds, security companies, insurance companies, asset under management (AUM) firms, and qualified foreign institutional investors (QFII) - is less than $15 \%$ as of 2013. More strikingly, trading activities by individual investors account for $82.24 \%$ of the total trading volume in $2013 .{ }^{2}$ It is well known in the

\footnotetext{
${ }^{2}$ Unfortunately, we do not have the breakdown data for SZSE. However, there are no reasons to believe that individual investors play a lesser role in SZSE as compared with SHSE. In fact, the percentage of stocking holding and the composition of trading volume by individual investors is more likely to be higher for SZSE than SHSE, as individual investors tend to hold small and speculative stocks, which are mostly listed in SZSE. This is also supported by the much higher turnover ratio in SZSE than in SHSE (see the last column of Panel A in Table A.2).
} 
financial literature that retail investors are highly influenced by sentiment. They hold less diversified portfolios, have more incentives to trade speculative stocks, and engage in unsophisticated trading strategies such as trend following or correlated trading (Feng \& Seasholes 2004; Kumar \& Lee 2006).

Second, as one of the leading emerging markets, the Chinese stock market is extremely liquid and has an unprecedented trading volume. As is shown in the last column of Panel A in Table A.2, on average, stocks in SHSE and SZSE are turned over at least 1.49 and 2.65 times in 2013, which is even higher than the average turnover ratio for many of the developed markets.

Third, the Chinese stock market is characterized by heavy regulation: Short-sales of stocks are prohibited by law. The stringent constraints on short selling make it very difficult to arbitrage away the mispricing at the market level as well as the stock level (Mei et al. 2009).

Fourth, the market has less openness to international investors. It only opens its door to foreign investors in November 2002. Only approved qualified foreign institutional investors (QFII) can invest in the Chinese A-share market, and they are subject to a number of rules and regulations (e.g. capital control) imposed by the local regulatory body.

Overall, given their large share holdings and frequent trading volume, retail investors (noise traders) have very strong market power in China's stock market. These unique investor features, which are distinct from developed markets, seems to weigh more on the sentimental demand from the noise traders. It provides an interesting "out-of-sample" test for the sentiment effect on stock returns under alternative settings.

\subsection{Relevant Literature}

In recent years, a prevailing view in finance is that investor sentiment, defined as the irrational belief formed by a subset of uninformed investors (e.g. noise traders), is a contrarian indicator of future stock returns at nearly all horizons (Fisher \& Statman 2000; Baker \& Wurgler 2007):

The contrarian hypothesis: The net effect of investor sentiment on subsequent returns is negative.

The contrarian view - a high (low) level of sentiment is linked with low (high) market returns in the subsequent periods - is rationalized by the theoretical work of Barberis et al. (1998), in which the representative, sentiment-prone agent extrapolates the current trend far into the future (the representative bias), makes erroneous bets on future market movements by pushing prices far 
away from the fundamental values, and eventually faces adverse consequences as "fads" do not live up to the facts (price revision).

A similar view is noted in Warther (1995). He formulates the "price-pressure" hypothesis that unwarranted sentimental demand (via aggregated mutual fund flows), which reflects no real information, exerts contemporaneous price pressure and is linked with lower expected returns in subsequent periods (price reversals). De Long et al. (1990a) argue that sentiment-induced mispricing provides profitable opportunities for arbitrageurs to buck the trend, the so-called "arbitrage effect", which also leads to a contrarian effect of investor sentiment on subsequent returns. Therefore, a negative relation between investor sentiment and subsequent market returns can be broadly perceived as indirect evidence that 1) noise traders systematically bet wrongly on the future direction of market movements, the "dumb money effect", and 2) rational speculators engage in price-stabilizing activities (e.g. arbitrage) to bring the market prices back to fundamental levels, the "smart money effect".

Empirically, ample evidence on long-run time-series predictability is provided from the US market (Baker \& Stein 2004; Brown \& Cliff 2005) and other developed markets (Schmeling 2009) to reassure the contrarian view. Moreover, the contrarian predictability of sentiment is more pronounced in the cross section (Baker \& Wurgler 2006; Frazzini \& Lamont 2008; Baker et al. 2012).

Despite its wide popularity, powerful tests in the above sentiment-induced return reversal pattern are, however, inherently difficult as there are no firm guidelines as to the appropriate time frame to be used in these tests (Warther 1995). At one extreme, researchers look for the forecasting power of sentiment at really short horizons (e.g. weekly or monthly), as in Brown and Cliff (2004). At the other extreme, the return predictability of sentiment from one to five year horizons is also heavily investigated by empiricists (Brown \& Cliff 2005; Schmeling 2009).

The uncertainty about the appropriate time frame to test the relation between investor sentiment and future market returns, at the very least, points to the fact that the documented long-run contrarian predictability of investor sentiment does not necessarily carry over to the short horizons, such as weekly or monthly frequency. On the one hand, high levels of investor sentiment, which is unjustifiable by the facts, can pose a warning sign for stock returns in the 
near term (a negative relation between sentiment and subsequent returns). On the other hand, the sentiment of investors is also likely to exert a persistent, positive effect on subsequent returns in the short run (a positive relation between sentiment and subsequent returns). A number of behavioral reasons or real-world mechanisms could contribute to such a positive mechanism between investor sentiment and future returns in the short run. Though the literature offers no fully specified model on the linkage between sentiment and short-term returns, a number of works give hints on the possible directions in which sentiment might impact on future returns in the short run, which we summarize in the next subsection on testable hypotheses.

\subsection{The Momentum Hypothesis}

The contrarian predictability of sentiment builds heavily on the efficiency of financial markets. That is, rational speculators (informed investors) stabilize the asset prices, bucking the trend induced by sentiment. It should be noted, however, that a number of real world mechanisms or frictions, which prevail in the financial markets, limit the arbitrage ability of rational speculators. As a result, mispricing could prevail for extended periods of time, and the level of sentiment could also serve as a momentum predictor for subsequent returns in the short run. This should not be surprising, as Kling and Gao (2008) find that investor sentiment follows a positive feedback process in the short run in China. Adding to this argument are the empirically observed year-long, self-feeding price bubbles in the history of Chinese stock market (e.g. the 2007 price bubble). We provide below a number of reasons for the alternative, momentum predictability of investor sentiment.

First, arbitrage — the activity to bring mispriced assets back to their fundamental level —is limited in practice (Shleifer \& Summers 1990). Unlike the theoretical assumption of an infinite horizon, rational speculators, such as institutional investors, typically have shorter investment horizons than noise traders (retail investors) in practice. The shorter horizon makes them concerned about the resale prices, in particular. The uncertainty due to noise trader risk suggests that betting against noise traders run the risk, at least in the short run, could incur huge financial losses if investor sentiment turns more extreme, and prices move further away from fundamental levels, the well known "create-space effect" (De Long et al. 1990a). Therefore, the concern about the resale price limits rational speculators' ability to take on price stabilization activities (arbitrage) in the short run. Adding to the nerve of rational institutional investors are the fundamental risk of 
the underlying (De Long et al. 1990a), the regular performance evaluation with their peers, and short-sales constraints (or the barrier of short-sales costs). All of these factors could contribute to the possibility that noise-trader-induced mispricing gets more pronounced over a protracted period of time, leading to a positive relation between investor sentiment and subsequent returns in the short turn.

Second, Shleifer and Summers (1990) warn that one of the strongest behavioral tendencies is to extrapolate or chase the trend. Investment is a social process: Sentiment investors are reinforced by each other hopping on the bandwagon (the so called "bandwagon effect"). Put differently, noise traders herd in and out of the market to engage in the trend-following strategy, causing prices to deviate further from their fundamental level. More dramatically, the "bandwagon effect" could persist for extended periods of time, as sentiment gets higher and higher over time and sequential (new) investors flooded into the market, which leads to the phenomenal "deposit drawdown effect" in China as documented in Burdekin and Redfern (2009). Using a sequential decision model, Banerjee (1992) shows that it makes sense for subsequent investors to underweight their own information and overweight the information of existing market participants, thereby leading to the herd behavior. The herd behavior also implies a broad wave of trend-chasing activities which widens the sentiment-induced mispricing in subsequent periods. Therefore, the trend-chasing behavior postulates a positive effect of sentiment on future returns.

A third reason is that even the rational speculators jump onto to the bandwagon and engage in price destabilizing activities, given the prevalence of the positive feedback traders (De Long et al. $\underline{1990 b}$ ). In anticipation of the future buying power of positive feedback traders as assumed in De Long et al. (1990b)'s model, rational speculators buys ahead of others to reap the profits in subsequent selling against positive feedback traders. The essence of the model is that informed rational speculators exploit the systematic bias of others who extrapolate trends far into the future by purchasing ahead of these positive feedback traders, pumping up the asset price, and triggering anticipated sentimental demand at many horizons. As long as positive feedback traders focus on sufficiently long investment horizons (based on their erroneous extrapolation), a series of positively correlated realized returns are expected in conjunction with their sentiment. Therefore, the implication of the model is consistent with a positive effect of sentiment on future returns. 
Overall, the possibility that misperception about future market movements gets more pronounced over a protracted period of time suggests a momentum predictability of investor sentiment for subsequent returns, at least in the short-term. In other words, a high level of sentiment leads to high stock returns in subsequent periods.

The momentum hypothesis: The net effect of investor sentiment on subsequent returns is positive.

\section{Data and Empirical Design}

\subsection{Sample Periods and Market Return Proxies}

This paper employs a comprehensive dataset of the Chinese A-shares, carefully constructed from several reliable sources (see Table 1). The sample period spans 17 years from 1997 to 2013. To properly characterize the overall performance of the market, we follow Fama and French (1993, 2012) and Frömmel and Han (2014) by calculating the total return (including dividends) of the market portfolio as the value-weighted average of all available individual stocks, which is free of survival bias. Following the convention, we use the monthly rate of the one-year bank term deposit in China as the risk-free rate. The excess market return is then the difference between the return of the market portfolio and the risk-free rate. Our proxy for the market excess returns covers both capital gains and dividend income, which is better than the Shanghai and Shenzhen Composite Indices that are pure price indices.

\section{[Insert Table 1 here]}

\subsection{The Investor Sentiment Index}

To properly measure the aggregated market sentiment in China, we start by searching for a number of reliable individual sentiment proxies: namely, market turnover ratio (TURN), number of newly opened individual investor accounts in Shanghai Stock Exchange (IIA), and valueweighted price-earning ratio $(P E)$ of the market. We are aware that there are no definitive or uncontroversial measures for market sentiment. In many cases, the sentiment proxies are country- 
specific and are subject to data availability. ${ }^{3}$ The inclusion of these individual sentiment measures in our study is mainly based on sound economic reasons, data consistency, and data availability. For example, market-wide turnover is considered as a direct measure of investor sentiment according to the theoretical justification in Baker and Stein (2004). A high market turnover ratio indicates high demand from the sentiment investors who push the rational investors out of the market, destabilizing asset prices. The number of newly opened investor accounts is also highly reflective of investor sentiment in China (Chen et al. 2014): Given the strong market power of retail investors in China, an increasing number of new accounts implies a larger (irrational) demand from retail investors. The inclusion of the price-earnings ratio follows the same logic of Indro (2004). As we do not have mutual fund flow data to estimate increased money flowing to the market, we use the valuation ratio as a direct proxy for the flow data. The logic is quite straightforward: As long as (more) money is pouring into the market, the valuation ratio will power higher. Historical episodes of dramatic price bubbles in China's stock markets are uniformly linked with unreasonably high valuation $(P E)$ events. In principle, all the three individual measures are good candidates for investor sentiment as they have greater values in bull markets and lower values in bear markets, reflecting a positive correlation with the investor mood. Moreover, these sentiment proxies are available for the entire sample period and have no artificial breaks in the time series.

To properly form a valid market-based sentiment index in China, we then follow carefully a number of statistical procedures as summarized below.

First, as noted in Baker and Wurgler (2007), individual sentiment proxies may have a deterministic trend which is not related to investor sentiment. For example, both turnover ratio and the number of newly opened individual investor accounts have an upward trend in our sample period, which reflects the unprecedented growth of China's capital market and the increased market participation by retail investors over time. Therefore, we follow the detrend

\footnotetext{
${ }^{3}$ For example, Baker and Wurgler $(2006,2007)$ construct a US sentiment index based on six individual components: the close-end fund discount, the NYSE share turnover, the number of IPOs, the average first-day return of IPOs, the equity share in new issues, and the dividend premium. However, in a later international study, Baker et al. (2012) admit data limitations and could only construct the country-specific sentiment index with four components: the volatility premium, the volume of IPOs, the average first-day return of IPOs, and market turnover. Other scholars advocate the use of alternative measures for sentiment, such as technical indicators and/or survey-based measures (Brown \& Cliff 2004, 2005; Lemmon \& Portniaguina 2006; Schmeling 2007, 2009).
} 
procedure as suggested in Baker and Wurgler (2007) and Chen et al. (2014) to scale individual sentiment proxies by their prior six-month moving average. The detrend procedure removes the (undesirable) deterministic trend and also helps to ensure the stationarity of the time series.

Second, as is noted in prior literature that shifts in these sentiment proxies have both a rational component and an irrational one. The rational component relates to the changes in macro fundamental, as sentiment investors receives a noisy signal about the overall economy (Verma \& $\underline{\text { Soydemir 2009). To remove, or at least alleviate, the "rational" effect, we follow Baker and }}$ $\underline{\text { Wurgler (2006) }}$ and Verma and Soydemir (2009)'s orthogonalization procedure by regressing each individual proxy on a set of macro variables (namely the growth of industrial production, growth of money supply, levels of short-term interest rates and foreign exchange rates). The residuals of the orthogonalization procedure are then the proxies for the irrational part of investor sentiment.

Third, we adopt the principal component approach (PCA) of Baker and Wurgler (2007) by extracting the first principal component from the three individual sentiment measures (the residuals) as the market-based investor sentiment index. ${ }^{4}$ In principle, the first principal component, which captures the common variation of the individual measures, should represent properly the time variation of (unobserved) market-wide investor sentiment in China.

The principal component procedure leads to the following sentiment index, denoted as $S^{P C A}$.

$$
S_{t}^{P C A}=0.570 T U R N_{t}^{O}+0.642 I I A_{t}^{O}+0.510 P E_{t}^{O}
$$

The first component explains $67 \%$ of the sample variance, well capturing the co-movement of individual sentiment proxies. We use the subscript $O$ to denote that all the three components are orthogonalized to the macroeconomic variations, capturing the irrational sentiment effects. All three proxies have the expected sign, confirming the positive relation with market sentiment. The PCA sentiment index places the most importance on $I I A^{O}$, as its coefficient is the largest in magnitude, reinforcing that the number of newly opened accounts gauges the irrational optimism among retail investors. For comparison purposes, we also construct a naïve sentiment index, denoted as $S^{\text {Naive }}$, which imposes equal weights on the three sentiment composites, and another

\footnotetext{
${ }^{4}$ The PCA proceeds as follows: First, we standardize the three sentiment proxies and obtain the eigenvalue and eigenvector of their covariance matrix. Second, the composite sentiment index is constructed as a linear combination of the three variables using the eigenvector associated with the largest eigenvalues as the corresponding weight.
} 
PCA sentiment index which excludes the less commonly used component $P E^{O}$, denoted as $S^{E x P E}$. In fact, these two alternative sentiment indices are highly correlated with the original PCA sentiment index, with correlation coefficients of $98 \%$ and $94 \%$, respectively.

Figure 1 plots the fluctuation of the PCA sentiment index together with the market excess returns in our sample periods. The most salient feature is that the sentiment index tracks closely the direction of market returns, implying a high correlation between the innovations of the two series. Moreover, a (preliminary) eye-ball test indicates the appropriateness of our sentiment index, as the peaks and troughs of the index are concurrent with the major episodes in China's stock market history. For example, the spike in June 1999 is probably a response to the reduction of the stamp tax of security transaction within that month, while the spikes in May 2006 and January 2007 are concurrent with the then-record daily transaction value of 55.3 billion and 100 billion Chinese yuan, respectively. The largest price crash (the post 2007 period) is also consistent with the consecutive pessimistic sentiment wave from October 2007 to October 2008.

\subsection{Descriptive Statistics}

Table 2 provides the summary statistics of the dataset. The arithmetic mean and standard deviation of the monthly market excess return are $0.16 \%$ and $8.07 \%$, respectively, indicating a monthly Sharpe ratio of 0.02 and a market price risk (defined as the ratio of market excess return to its variance) at around 0.25 . One important note is that the relatively low market price of risk, which reflects the implied risk aversion of an average investor, suggests that Chinese investors are generally less risk averse as compared with investors in developed markets. ${ }^{5}$ The high return volatility, low Sharpe ratio, and lower degree of risk aversion are, however, in line with the general perception of a speculative market as described in Section 2.1. The sentiment indices, the three individual sentiment components, and other economic variables are all standardized with mean zero and unit variance, which will facilitate the comparison of their economic significance in later predictive regression. Consistent with the literature, all the predicting variables seem quite persistent, indicated by their first-order autocorrelation coefficient. In contrast, the market excess return exhibits no serial correlation effect, as its first-order autocorrelation coefficient is virtually zero. The time-series plots of these economic and financial variables are available in Figure A.1 in the appendix.

\footnotetext{
${ }^{5}$ The historical market price of risk in the United States is between 1.5 and 4 in Bodie et al. (2012).
} 
The lower part of Table 2 presents the cross-correlation coefficients of the dataset. Several prominent features are worth noting. First, the market excess return is highly correlated with the PCA sentiment index and its three components. The positive contemporaneous correlation is consistent with Figure 1 that increased sentiment level will push up asset price and lead to increased return during the current period (the "price pressure"). It also reinforces the need to adopt a bias-reduction technique in our later estimation because the innovations of both sentiment and market return are highly correlated. Second, the three sentiment components are highly correlated with each other, reinforcing their validity as the proxies for market sentiment. The orthogonalized $P E$ ratio has only a correlation coefficient of 0.26 with the unorthogonalized $P E$ ratio, much less than its correlation with IIA sentiment proxy, which lends further support for its validity as a proxy for the (irrational) sentiment measure. Third, the consumer confidence index (CCI), a survey-based sentiment measure, is not correlated with contemporaneous returns. Nor does it directly correlate with all the market-based sentiment proxies as the coefficients are slightly negative, which further challenges its validity as a sentiment proxy in China. While some studies tend to use CCI as a proxy for investor sentiment (Schmeling 2009), we should point out that CCI concerns consumers' general expectations about the overall prospects of the economy rather than the stock market. This is indeed the case, as CCI is positively correlated with other economic variables (such as BCI, IP, and PE ratio). We have more to say about CCI in our later analysis.

[Insert Table 2 here]

\section{Time-series Analysis}

\subsection{Short-term Return Predictability}

\subsubsection{Single-factor Predictive Regression}

The predictive regression with a single predictor variable is by far the most heavily studied and commonly used in the literature. Hence, it forms the baseline model in establishing the relation between sentiment and market returns.

$$
R_{t+1}=\alpha+\beta S_{t}+u_{t+1}
$$


where $R_{t+1}$ is the market return in excess of the risk-free rate in period $t+1, S_{t}$ is the (lagged) sentiment proxy (or other predicting variable) measured at the end of period $t$. We test the null hypothesis $\left(H_{0}: \beta=0\right)$ that investor sentiment has no predictive ability by evaluating the slope coefficient.

As our interest is to perform hypothesis testing on the slope coefficient in the predictive model, several econometric issues may well arise if we use the conventional OLS estimation procedures. First, there is potentially a spurious regression concern when the predictor is highly persistent (Ferson et al. 2003). Second, the OLS method produces biased coefficient in finite samples, the well-known Stambaugh (1999) small-sample bias, when the regressor is (highly) persistent and its innovations are correlated with those of the dependent variable. Note also that in our case the beta coefficient is downward biased (towards zero), as the innovations of the two time series are positively correlated. The magnitude of the potential downward bias in the OLS estimate is illustrated by the simulation evidence in Appendix A.

To properly tackle the above mentioned econometric issues, we apply the multiple augmented regression method (mARM hereafter) of Amihud et al. (2009) to obtain the bias-reduced estimates of the slope coefficient on sentiment. We are aware that there are a number of alternative bias-reduction techniques proposed in the literature, such as the univariate augmented regression method (uARM hereafter) of Amihud and Hurvich (2004) and the moving-block jackknife method (MBJK hereafter) of Zhu (2013). Our choice of the mARM method is based on the good finite sample performance as indicated in the simulation evidence in Appendix A.

The mARM method in Amihud et al. (2009) proceeds by running an auxiliary AR(1) regression on the predictor variable, $S_{t}{ }^{6}$

$$
S_{t+1}=\theta^{c}+\rho^{c} S_{t}+v_{t+1}^{c}
$$

where the superscript $c$ denotes the bias-corrected estimates obtained by iterating on the Nicholls and Pope (1988) expression for the analytical bias of the OLS regression for the AR(1) process. ${ }^{7}$ According to Amihud et al. (2009), the bias-reduced estimator of the slope coefficient $\beta$ in the

\footnotetext{
${ }^{6}$ Throughout the article, we use the term UARM and mARM to refer to the bias-reduction method in Amihud and Hurvich (2004) and Amihud et al. (2009), respectively. It should be noted that both methods are flexible enough to accommodate predictive regressions with single regressor and multiple regressors as well.

${ }^{7}$ For brevity, we refer readers to Amihud et al. (2009) regarding the technical details on the iterative procedure.
} 
predictive regression is achieved by augmenting Eq. [4.1] with the bias-corrected error term $v_{t+1}^{c}$, obtained from the auxiliary $\operatorname{AR}(1)$ regression in Eq. [4.2]. The statistical significance of the slope coefficient is based on the $t$-statistics associated with the Newey-West adjusted standard errors.

For robustness of our hypothesis testing, we also report separately the empirical $p$-values based on the wild bootstrap procedure used in Huang et al. (2014). The wild bootstrap procedure takes into account the persistence in predictors, correlations between the innovations of market returns and those of predictors, and general forms of return distribution (e.g. heavy tails). ${ }^{8}$ In unreported analysis, we also perform the $t$-tests based on the adjusted standard errors according to the analytical expressions suggested in Amihud and Hurvich (2004) and Amihud et al. (2009). Results for the significance of the slope coefficients are very similar, and thus omitted for brevity purposes.

Table 3 presents the estimation results of the predictive regression. Panel A reports the baseline results using our PCA sentiment index, $S^{P C A}$, constructed from the three individual sentiment components. Contrary to the prevailing view that sentiment is a contrarian predictor, we find that the PCA sentiment index is a momentum predictor over the entire sample period: Lagged sentiment is positively associated with the excess market return in the subsequent month with an OLS slope coefficient of $1.38 \%$. The positive coefficient is statistically significant at the $5 \%$ level based on the Newey-West $t$-statistics as well as the wild bootstrapped $t$-statistics (see the empirical $p$-value). When correcting for the finite sample bias using the mARM method, the slope coefficient becomes even larger in magnitude than the OLS estimator. The downward bias in OLS estimation is as expected, given that the forecast error in returns and innovations in investor sentiment are positively correlated (see also our simulation evidence in Appendix A). The bias-adjusted slope coefficient is around 1.50\% under Amihud et al. (2009)'s mARM method. That is, a one-standard-deviation rise (drop) in sentiment increases (reduces) expected market returns over the next month by approximately $1.50 \%$. Recall (from Table 2) that the sample average of the monthly excess market return in China is only $0.16 \%$, thus the magnitude of the slope coefficient implies that the expected excess market return varies by about nine times larger than its average level, signaling strong economic significance. It seems tempting to extrapolate this return predictability to an annual basis by a multiplication factor of 12 , which

\footnotetext{
${ }^{8}$ A walk-through of the wild bootstrap method is detailed in the appendix of Huang et al. (2014).
} 
indicates an annualized value of around 18\%. This, however, seems unreasonable because sentiment is mean-reverting and A high (low) sentiment level indicates lower return in the long run, which we will analyze further in Section 4.2.

The $R^{2}$ of the OLS regression for the entire sample period is around 2.95\%. Empirically, this is comparable with, or slighter higher than, that of conventional return predictors at short horizons (Goyal \& Welch 2008), where the typical explanatory power of a return predictor ranges between $0.3 \%$ and $5 \%$ at the monthly frequency. The $R^{2}$ of the mARM regression increases substantially as expected because the model includes the innovations from the auxiliary regression in Eq. [4.2], a contemporaneous term, which significantly increases the explanatory power of the variation in stock returns.

To check whether the predicting power of sentiment is stable over time, we divide the full sample into two subsamples with more or less equivalent length: One spans from 1997 to 2005 and the other spans from 2006 to 2013. The positive return predictability of sentiment remains statistically significant in both cases, indicating a very stable predictive pattern at the monthly frequency. Interestingly, the magnitude of the slope coefficient seems more pronounced in the second subsample (2006-2013) than the first subsample (1997-2005). The enlarged sentiment effect over time is in line with the fact that the second subsample is characterized by more dramatic market shifts (e.g. the 2006-2007 price bubble and the 2007-2008 financial crisis).

Panel B reports the estimation results using each of the individual sentiment components as the regressor. The results are highly consistent with that of the PCA sentiment index: The slope coefficients of $T U R N^{O}, I I A^{O}$, and $P E^{O}$ all have the expected positive sign and are all statistically significant, as demonstrated by the empirical $p$-values. The magnitude of the bias-reduced slope coefficients ranges between $0.91 \%$ and $1.77 \%$ on a monthly basis, again signaling strong economic significance. The $R^{2}$ s of the OLS predictive regression range from $1.10 \%$ to $3.64 \%$. It seems clear that the forecasting power of our constructed PCA sentiment index comes directly from the three underlying components. Although each individual component can be used as a valid sentiment proxy and produces significant output, we weigh more on our constructed PCA sentiment index, as the PCA procedure removes the idiosyncratic noises contained in the individual proxies, if any (Baker \& Wurgler 2006, 2007). 
For comparison, we report in Panel $\mathbf{C}$ the estimation results for the three alternative sentiment indices. First, the equally weighted naïve sentiment index, $S^{\text {Naive }}$, has similarly strong forecasting power as our PCA sentiment index. The bias-reduced slope coefficient is $1.53 \%$ during the entire sample period. Second, recall from Panel B, it seems that $P E^{O}$ is a stronger predictor than the other two conventional sentiment proxies. To address the suspicion that our baseline result is mainly driven by one single predictor, we construct the $S^{E x P E}$ index, which includes only TURN $N^{O}$ and $I I A^{O}$. Not surprisingly, the $S^{E x P E}$ index has very similar predictive features as the $S^{P C A}$ index, although the slope coefficient and the $R^{2}$ of the OLS regression is a bit smaller in magnitude: The bias-adjusted coefficient is $1.12 \%$, which is significant at the $5 \%$ level, and the $R^{2}$ of the OLS regression is $1.70 \%$. The similar predictability from the $S^{E x P E}$ index demonstrates the robustness of our baseline results, as they are not driven by the inclusion of a single sentiment proxy. Finally, the estimation results for the survey-based sentiment measure, CCI, is disappointing as its slope coefficient is virtually zero under both the OLS and mARM methods, indicating no return predictability at all. The inability to forecast returns in combination with its low correlation with all other (market-based) sentiment proxies (as shown in Table 2) poses challenges for the validity of CCI as a sentiment measure. In fact, CCI might be a poor measure for investor sentiment for a number of reasons. First, by definition, CCI measures consumers' general expectations about the overall prospects of the economy rather than the stock market. Second and more critically, as a survey-based measure, there is always the concern of "what they say is not what they act", meaning that the survey respondents do not really act in the way they indicated in the survey. Another concern is that CCI might reflect a rational expectation, rather than the irrational belief of sentiment investors. Therefore, all of these facts cast doubt on $\mathrm{CCI}$ as a valid sentiment proxy in our application.

\section{[Insert Table 3 here]}

\subsubsection{Multi-factor Predictive Regression}

We note that some criticism might arise that the predictive power of investor sentiment is mainly a manifestation of the shifts in fundamentals driven by business or economic cycles. To alleviate this concern, we first employ several macroeconomic variables, including business cycle indicator (BCI), industrial production (IP), and aggregated (value-weighted) PE ratio, as valid proxies for the economic fundamentals. We then examine whether the return predictability of 
sentiment is robust after controlling for these fundamental effects with multivariate predictive regressions. Following the convention in the literature, we conduct the following multiple-factor predictive regressions based on the sentiment index, $S_{t}^{P C A}$, and a vector of the control variables, $Z_{t}$.

$$
R_{t+1}=\alpha+\beta S_{t}^{P C A}+\psi^{\prime} Z_{t}+\varepsilon_{t+1}
$$

Again, our interest is in the slope coefficient, $\beta$, which measures the marginal effect of the (lagged) sentiment level on subsequent market returns, after accounting for the effects of control $\operatorname{variable}(\mathrm{s})$.

The first three model specifications in Table 4 report the bias-adjusted mARM estimation results based on bivariate predictive regression, in which we include the PCA sentiment index and one of the economic variables each at a time. Across the three model specifications, the slope coefficient $\beta$ on our sentiment index is very robust, as it has the same positive sign and its magnitude is more or less similar in all three cases, ranging from $1.34 \%$ to $1.52 \%$, a result highly similar to that in the univariate regression. The uniform results in the bivariate regression confirm that the return predictability of sentiment is not purely due to the shifts in fundamentals (e.g. business cycles, industrial expansion, and market valuation effects).

The last row of Table 4 reports the result for the so-called Kitchen Sink model, in which we include sentiment and the three economic variables all together. The advantage of the Kitchen Sink model is that it could increase the explanatory power of the predictive regression. However, the downside is that the heavily parameterized model with potentially highly correlated regressors might suffer from over-parameterization problem. Again, we find a very similar and consistent pattern: The bias-adjusted slope coefficient on $S_{t}^{P C A}$ is significantly positive and large in magnitude $(1.39 \%)$, which is very similar to the case of the single-predictor regression in Table 3. The slope coefficients on IP and PE seem also significant with the Newey-West $t$ statistics. However, when checking the empirical $p$-values generated from the wild-bootstrap testing procedure, only the slope coefficient on $S_{t}^{P C A}$ is statistically significant. To sum up, the incremental predictive effect of $S_{t}^{P C A}$ are very robust, as it remains both statistically and economically significant after controlling for macro fundamentals under all four model specifications. 
[Insert Table 4 here]

\subsubsection{Out-of-sample Predictability}

In this subsection, we address the well-known Goyal and Welch (2008)'s challenge, a legitimate concern that whether the strong monthly return predictability documented in the in-sample analysis will be carried over to the out-of-sample period. In principle, an over-fitted predictive model tend to deliver better in-sample forecasting performance, while such return predictability is not sustained out of sample. Therefore, the out-of-sample test is the most relevant for assessing genuine return predictability in real time as it avoids the over-parameterization issue (Goyal \& Welch 2008). ${ }^{9}$ A somewhat related aim of the out-of-sample analysis is also to assess whether bias-reduction techniques such as mARM, uARM, and MBJK are able to provide enhanced forecasting performance out of sample.

For the out-of-sample analysis we retain an in-sample period from 1997 to 2006 to parameterize our model, and use the remaining seven-year out-of-sample period to evaluate the forecasting performance. In general, there is a trade-off between having sufficient in-sample observations for a reliable estimation of model parameters and resuming a relatively long out-of-sample period for forecasting evaluation. Given the relatively short history of China's stock market which unfortunately limits the sample size, our choice of the out-of-sample period well balances the above-mentioned trade-off. Furthermore, we adopt a recursive estimation scheme for the insample model estimation and form the out-of-sample forecast for period $t+1$ with the following single-factor predictive model:

$$
E_{t}\left(R_{t+1}\right)=\hat{\alpha}_{t}^{m}+\hat{\beta}_{t}^{m} S_{t}
$$

where $\hat{\alpha}_{t}^{m}$ and $\hat{\beta}_{t}^{m}$ are the regression coefficients estimated recursively using data from period 1 to period $t$. The superscript $m$ denotes the alternative estimation methods to obtain the fitted values, $m \in\{O L S, m A R M, u A R M, M B J K\}$. $S_{t}$ denotes the predictor variable measured at the end of period $t$. To avoid the forward-looking bias in the original PCA sentiment index which is constructed from the entire sample, the PCA sentiment index used in Eq. [4.4] is also estimated

\footnotetext{
${ }^{9}$ According to Huang et al. (2014), out-of-sample tests also suffers less from small-sample size distortions such as the Stambaugh (1999) bias.
} 
recursively each time using real-time information up to period $t$. Note that the forecasting model can also be augmented to include other predictor variables. ${ }^{10}$

To take up the challenge from Goyal and Welch (2008), we compare the out-of-sample forecasts from the predictive model in Eq. [4.4] with the historical average as the benchmark. The historical average forecast corresponds to a constant return model, a nested version of the predictive model in Eq. [4.4] with the slope coefficient set as zero. Intuitively, if the underlying return process is generated by a constant plus a random noise, the predictive model in Eq. [4.4] produces a noisier forecast than the historical average because it estimates the slope coefficient with zero population values. In other words, we would expect the benchmark model to generate a smaller (or equivalent) mean squared forecast error (MSFE) than our predictive model. To properly evaluate this assertion, we calculate the widely used out-of-sample $R_{O S}^{2}$ statistic, the Diebold and Mariano (1995) $t$-statistic, and the Clark and West (2007) MSFE-adjusted statistic.

The $R_{O S}^{2}$ statistic measures the proportional reduction in MSFE for the predictive regression forecast relative to the historical average benchmark (Campbell \& Thompson 2008). It is computed as follows.

$$
R_{O S}^{2}=1-\frac{\sum_{t=p}^{T-1}\left(R_{t+1}-E_{t}\left(R_{t+1}\right)\right)^{2}}{\sum_{t=p}^{T-1}\left(R_{t+1}-\bar{R}_{t+1}\right)^{2}}
$$

where $R_{t+1}$ denotes the realized excess market return in period $t+1, E_{t}\left(R_{t+1}\right)$ the forecast from the predictive model at the end of period $t$. The length of the in-sample period is denoted as $p$, while $T$ is the total number of observations. $\bar{R}_{t+1}$ is the historical average (benchmark) at the end of period $t$ calculated as in Eq. [4.6].

$$
\bar{R}_{t+1}=\frac{1}{t} \sum_{i=1}^{t} R_{i}
$$

By construction, the $R_{O S}^{2}$ statistic lies within the range $(-\infty, 1]$. A positive value of $R_{O S}^{2}$ indicates that the forecast $E_{t}\left(R_{t+1}\right)$ outperforms the benchmark $\bar{R}_{t+1}$ in terms of MSFE.

\footnotetext{
${ }^{10}$ The model specification for the augmented predictive model will be as follows: $E_{t}\left(R_{t+1}\right)=\hat{\alpha}_{t}^{m}+\hat{\beta}_{t}^{m} S_{t}+\widehat{\psi}_{t}^{m} Z_{t}$, where $Z_{t}$ is the vector of other predictor variables.
} 
The Diebold and Mariano (1995) test (DM-test hereafter) evaluates whether two forecasts offer the same forecasting accuracy. In this case, we test the null hypothesis that the historical average has a smaller or equivalent MSFE than that of the predictive regression model.

In a similar vein, the MSFE-adjusted statistic due to Clark and West (2007), also evaluates the null hypothesis that forecast error (measured by MSFE) for the historical average is less than or equal to that produced by the predictive regression model.

Panel A of Table 5 reports the out-of-sample forecast performance of sentiment using Eq. [4.4]. In the case of the PCA sentiment index, the OLS forecast model generates a positive $R_{O S}^{2}$ statistic of $3.45 \%$, indicating a smaller MSFE than the historical average. The values of the $R_{O S}^{2}$ become even more positive, indicating more precise forecasting performance (smaller MSFE) under the two alternative bias-reduction techniques, the mARM and UARM methods, than their OLS counterparts. In terms of the statistical significance of the outperformance, the DM-test statistic is not significant, but the $\mathrm{CW}$-test statistics are all significant at the $10 \%$ level for the four competing forecasts using OLS or bias-reduction techniques (mARM, uARM, and MBJK).

For comparison purposes, we also generate a (recursive) naïve sentiment index, which imposes equal weights on the three composites to form the sentiment index. We find a very similar pattern for the naïve sentiment index, as the predictive model delivers better forecasts than the historical average, revealed by the positive $R_{O S}^{2}$ values of $3.54 \%$. The forecasts using mARM and uARM bias-reduction techniques are also better than the OLS counterpart. Similar to the findings in the PCA sentiment index, the CW-test statistics are all significant at the $10 \%$ level for the four competing forecasts using OLS or bias-reduction techniques (mARM, uARM, and MBJK).

Panel B of Table 5 reports the forecasting performance of bivariate predictive regressions with one predictor being fixed as the PCA sentiment index, while the other is the BCI, IP, or PE one at a time. The idea to augment the forecast model with additional predictor(s) is to exploit a (potentially) larger price-related information set. The downside, however, is that including nonrelevant variable(s) might increase noise in the model estimation and leads to worse forecasting performance. For all three bivariate forecasting models, we find very similar out-of-sample performance: The $R_{O S}^{2}$ values are positive, indicating superiority over the historical benchmark. However, a closer examination reveals that none of the $R_{O S}^{2}$ values are more positive than their 
counterparts in the univariate case with sentiment index as the sole predictor. The forecasting errors (MSFE) are also larger than their counterparts in the univariate case and the DM-test and $\mathrm{CW}$-test statistics also seem less significant in most situations. The weaker performance is possibly because the economic variables (BCI, IP, and PE) have very little or no predictive power for subsequent market returns, and the inclusion of them only adds additional noise to the out-ofsample forecast. ${ }^{11}$

Summarizing the findings in Table 5, we find strong evidence that investor sentiment predicts subsequent market returns out of sample. In many cases, the out-of-sample forecasting ability can be further improved by bias-reduction techniques, in particular the mARM methods, which is also consistent with findings in prior subsections.

[Insert Table 5 here]

\subsubsection{Portfolio Implications: Market Timing Strategies}

To shed lights on its portfolio implications, we propose a simple, modified market timing strategy, which shifts between the risky and risk-free assets based on the received trading signals. The design of the strategy is consistent with the short-sales constraints in China: At the end of each month, the investor will take a long position of the market portfolio over the next month, if he or she receives a buy signal. Otherwise the investor will liquidate the market portfolio and use the proceeds to invest in the risk-free asset. For comparison, we adopt three different sets of trading signals for the market timing exercise: The first set is based on lagged sentiment. When the lagged value of the sentiment index is above zero, it is defined as a buy signal. The intuition behind this is that whenever the market sentiment is above average, we expect the subsequent stock return will increase and thus take a long position in the equity market. The second set is based on the predicted value of the market excess return, generated by the forecasting model with sentiment as the predictor. If the expected market excess return is positive, it is then considered as a buy signal. The last set is the long-only version of the time-series momentum strategy in Moskowitz et al. (2012), denoted as TSMOM: A buy signal emerges when the cumulative returns over the prior 12 months (excluding the most recent month) is positive. Following the convention,

\footnotetext{
${ }^{11}$ In unreported analysis, we also consider the return forecasts from the Kitchen Sink model in Table 4 (the multivariate case); the out-of-sample performance is even worse than the bivariate cases and are thus omitted for brevity purpose.
} 
we use the buy-and-hold strategy as the benchmark to evaluate the economic gain from the different sets of trading signals. As there is no particular reason to restrict the holding period to be one month, we also vary the holding period from one month up to 12 months. We use the methodology of Jegadeesh and Titman (1993) with active portfolios to derive the single time series of the monthly returns for all holding periods larger than one month. Again, the out-ofsample evaluation period is from January 2007 to December 2013. The excess return of the timing strategy is, therefore, calculated as follows:

$$
R_{t+1: t+h}^{P}=\text { Signal }_{t} \times R_{t+1: t+h}
$$

where $R_{t+1: t+h}$ is the realized excess return of the market portfolio in the holding period (from month $t+1$ to $t+h$, and Signal $t_{t}$ is the trading signal received at the end of month $t$. Signal equals one when it is a buy signal, and zero otherwise.

Panel A and B of Table 6 report the mean returns and Sharpe ratios, respectively, for the benchmark buy-and-hold strategy and the timing strategies based on various signals. A number of observations are in order. First, the benchmark buy-and-hold strategy incurs a loss during the entire evaluation period: The annualized mean excess return is $-1.40 \%$ and its associated Sharpe ratio is -0.04 . This, however, is not surprising, given that the evaluation period encompasses the recent global financial crisis when the Chinese equity market melted down as well.

Second, the market timing strategy based on the signal of the lagged sentiment (the 2nd row) has a remarkable $10.75 \%$ excess return per annum for the one-month holding period, and its associated Sharpe ratio is 0.52 , which is far better than the buy-and-hold strategy. Looking across the different holding periods, there are further improvements in the portfolio performances (i.e. excess return and Sharpe ratio) when the holding period varies from two to five months. Similarly, the strategy based on the forecasted excess returns generated by the sentiment model (the next four rows) also deliver great performance as the average excess return for the onemonth holding period ranges between $4.75 \%$ and $5.95 \%$ per year. Looking across the different holding periods, it seems optimal to set holding periods between two to four months as the Sharpe ratios are generally better within these holding periods.

Third, in comparison, the long-only version of the time-series momentum strategy in Moskowitz et al. (2012) has only a moderate excess return of $0.11 \%$ per year, though it is still better than the 
benchmark buy-and-hold strategy. The TSMOM strategy does improve to $3.12 \%$ when the holding period is two months, but in general, its performance is far worse than that based on the sentiment signals or the sentiment-based return signals. The underperformance of the TSMOM strategy in the out-of-sample exercise is, however, in line with the recent evidence in the literature: First, Georgopoulou and Wang (2016) find that the TSMOM strategy breaks down during the recent crisis period across a number of developed and emerging markets. Second, Kim et al. (2016) find that the TSMOM profit mainly stems from the risk parity approach (volatility scheme) adopted in Moskowitz et al. (2012)'s paper. After accounting for the volatility scheme, they conclude that the performance of the TSMOM strategy is indistinguishable from that of the buy-and-hold strategy.

The fact that our sentiment-based market timing strategy outperforms the TSMOM strategy during the evaluation period reinforces the superiority of using investor sentiment to predict market returns. That is, lagged investor sentiment is a much stronger return predictor than lagged returns. After all, past returns are a noisy signal for future market movements (Levine \& Pedersen 2016). More importantly, it also leads to another point: The information content extracted from the sentiment signal is not subsumed by the dynamics of lagged returns, as the TSMOM strategy relying on the autocorrelation in returns is challenged in the crisis periods (Moskowitz et al. 2012; Georgopoulou \& Wang 2016).

Panel C of Table 6 provides more insights into the risk-adjusted performance of the market timing strategy by estimating the augmented Fama-French four-factor model. For brevity, we report only the results of the pooled regression for the timing strategy based on the lagged sentiment value and the TSMOM strategy, respectively. As it stands, the timing strategy with lagged sentiment earns a risk-adjusted return of $0.85 \%$ per month, which is significant at the $5 \%$ level. Moreover, the strategy loads positively on the market factor and the value factor at the $1 \%$ and $10 \%$ significance levels, respectively. Interestingly, the coefficient on the momentum factor is negative, which provides additional evidence that the "sentiment" impact is not mainly driven by past return dynamics.

In comparison, the TSMOM strategy earns a risk-adjusted return of $0.40 \%$, which is not statistically significant. The strategy loads significantly on the market, value, and momentum factors. The positive loadings on the momentum factor is consistent with the earlier findings that 
the returns of the cross-sectional and time-series momentum strategies are highly positively correlated (Moskowitz et al. 2012).

Summing up the results in Table 6, we find consistent evidence that investor sentiment is a strong momentum signal at the monthly frequency and its forecasting power can be translated into significant economic gains when implementing the market timing strategy based on the sentiment-related trading signals. In Appendix B, we provide additional evidence using the conventional asset allocation exercise for a mean-variance investor (DeMiguel et al. 2009), which further supports the finding that the improved forecasting ability with investor sentiment can translate into economically relevant gains for a mean-variance investor.

[Insert Table 6 here]

\subsection{Long-term Return Predictability}

\subsubsection{Long-horizon Predictive Regression}

In this subsection, we shift our focus to the long-run forecasting power of investor sentiment. So far, the empirical literature has produced strong evidence that market sentiment is a contrarian return predictor in the long run (Baker \& Stein 2004; Brown \& Cliff 2005; Baker et al. 2012). This strand of literature usually adopts the following multi-horizon predictive regression

$$
R_{t+1: t+h}=\alpha+\beta S_{t}+u_{t+1: t+h}
$$

where $R_{t+1: t+h}$ is the excess return cumulated (or averaged) over the period $t+1$ to $t+h, S_{t}$ is the $h$-period lagged predictor (e.g. sentiment proxy) measured at the end of period $t$. The null hypothesis for testing $\left(H_{0}: \beta=0\right)$ is that the predictor has no predictive ability.

For example, Huang et al. (2014) find that investor sentiment predicts negatively future market returns from one month up to 12 months. They attribute the empirical pattern of long-run sentiment effect to the classical behavioral argument of limit-of-arbitrage. In the long run, market gradually corrects mispricing as it cannot eliminate mispricing in a short period of time. Similarly, $\underline{\text { Schmeling (2009) }}$ provides international evidence across 18 advanced economies that investor sentiment is a contrarian predictor at one-, six-, 12-, and 24-month horizon. 
Despite the growing evidence of the long-run contrarian predictability of sentiment in the financial markets, the above estimation method and its associated results, however, are not without substantial debates (Boudoukh et al. 2008). To overcome the problematic issues of using overlapping returns as the dependent variable and the level of persistence of predictive variable, we opt for an alternative route to investigate the term structure of return predictability for investor sentiment. To be specific, we consider the following predictive regression for return horizons range from one month to 60 months. ${ }^{12}$

$$
R_{t+h}=\alpha+\beta S_{t}+\psi^{\prime} Z_{t}+u_{t+h}
$$

where $R_{t+h}$ is the market excess return in the period $t+h, S_{t}$ is the $h$-period lagged predictor (sentiment proxy) measured at the end of period $t$. We also include a vector of conventional macro variables to control for the shifts in fundamentals. The additional control variables are business cycle indicator (BCI), industrial production (IP), and aggregated PE ratio similar to subsection 4.1.2. Again, we test the null hypothesis $\left(H_{0}: \beta=0\right)$ that investor sentiment has no predictive ability by evaluating the slope coefficient. For robustness, we also test an alternative model specification based on the sign of the lagged sentiment, and present the results in

\section{Appendix C.}

Figure 2 plots the $t$-statistics from the predictive regressions across different time horizons (one to 60 months), using the PCA sentiment index as the return predictor. For robustness, we report the estimation results under alternative estimation techniques (OLS, mARM, uARM, and MBJK). A careful investigation of the four plots reveals the following patterns. First, market sentiment is a strong momentum signal in the short run (e.g. the first year). The $t$-statistics for the first eight consecutive months are all positive, with three out of them are significant at the 5\% level. The momentum trend is the most pronounced at the one-, two-, and seven-month lag. Second, immediately following the short-term momentum pattern, $t$-statistics turn negative and become more significant over the subsequent months (i.e. from the ninth month to the 21 st month). The change in the sign of the slope coefficients indicates that sentiment reverts to being a contrarian predictor over the subsequent periods. Moreover, starting from the ninth month till the 60th month, we find that the majority of the $t$-statistics (36 out of 52) are negative, indicating market sentiment predicts negatively market returns in the long run. In particular, the $t$-statistics at the

\footnotetext{
${ }^{12} \mathrm{We}$ are highly indebted to an anonymous referee for suggesting this estimation model over the problematic longrun predictive model in Equation [4.8].
} 
long end of the term structure (from the 47th month to the 60th month) are all negative, with six out of them are significant at the $10 \%$ level, reinforcing the notion expressed in Baker and Wurgler (2007) that the contrarian predictability of sentiment is linked with market revisions over time.

In unreported robustness checks, we also test the multi-horizon predictive pattern of each of the three sentiment components $\left(T U R N_{t}^{O}, I I A_{t}^{O}\right.$, and $\left.P E_{t}^{O}\right)$ separately. Again we find very similar pattern that the sentiment proxy shifts from a short-term momentum predictor to a long-term contrarian predictor. In fact, for certain sentiment proxy (such as $T U R N_{t}^{O}$ ), the short-term momentum patterns last for even longer horizons than eight consecutive months as for the PCA sentiment index.

To sum up, we find a very striking and robust term structure with different sentiment proxies and under alternative estimation methods. That is, investor sentiment shifts from a momentum predictor mainly within the first year to a contrarian predictor in the relatively longer horizons (approximately from the second year onwards), which is consistent with the short-term momentum hypothesis and the long-term contrarian hypotheses developed in Section 2.

\subsubsection{Impact of Global Sentiment}

In this subsection, we take a further step by investigating the (possible) contagious effect of global sentiment on China's local stock market. Prior literature suggests that sentiment spreads across markets, as country-level sentiments are positively correlated with each other (Baker et al. 2012). Using a panel regression in which they regress the monthly country-level returns on the beginning-of-year global and local sentiment, Baker et al. (2012) find strong evidence that global sentiment is a contrarian predictor of country-level returns. ${ }^{13}$ However, the time-series effect of local sentiment becomes trivial after controlling for the spillover from global sentiment.

It should be noted that emerging markets typically are less open to the global financial markets than developed markets. For example, only qualified foreign institutional investors (QFII) are able to invest in the Chinese A-share market, and they are subjected to capital controls by the local regulator body. The restriction on the market participation of international investors

\footnotetext{
${ }^{13}$ In Baker et al. (2012) the global sentiment is formed by extracting the common component from the six countrylevel sentiment indices using the principle component method.
} 
weakens the link between local sentiment and global sentiment. Accordingly, our market-based sentiment index has a slightly negative correlation of $-13.5 \%$ with the US sentiment index during our sample periods (see Figure 3). Therefore, prior evidence on global sentiment from the advanced economies might be misleading for the emerging markets. Whether and how global sentiment spills over to the Chinese local market remains an interesting, unexplored empirical question. To establish the link between China's stock returns and global sentiment, we estimate the following augmented long-horizon predictive models.

$$
R_{t+h}=\alpha+\beta_{1} S_{t}^{\text {Local }}+\beta_{2} S_{t}^{\text {Global }}+\psi^{\prime} Z_{t}+u_{t+h}
$$

where $R_{t+h}$ is the monthly market excess return over the period $t+h, S_{t}^{\text {Local }}$ is the (lagged) local sentiment measured at the end of period $t$. For our analysis, we use again the PCA sentiment index. For the (lagged) global sentiment index, $S_{t}^{\text {Global }}$, we use the Baker and Wurgler (2007) US sentiment index as a valid proxy. ${ }^{14}$ Unfortunately, the US sentiment index ends at the end of 2010, which shortens the sample size for our analysis. Both sentiment indices are re-standardized to have zero mean and unit variance during the estimation period to facilitate the interpretation of the economic relevance. Again, we test whether the slope coefficients on these sentiment indices are statistically different from zero.

Figures 4 and 5 plot the $t$-statistics for the local and global sentiment indexes from the multihorizon predictive regression using the OLS and mARM estimation methods, respectively. The empirical patterns are very similar under the two estimation methods. First, the multi-horizon predictive pattern for the local PCA sentiment index remains virtually intact as compared with the pattern in Figure 2: It serves as a strong momentum predictor in the short run and gradually turns to a contrarian signal in the long run. Second, and more interestingly, we find that global sentiment does have a substantial impact on China's stock market. However, the impact from global sentiment is not immediate, as none of the slope coefficients on $S_{t}^{\text {Global }}$ are significant at the 5\% level during the first two years. After approximately two years, global sentiment does seem to be a warning sign for the local stock market. The dramatic negative impact from the global sentiment is mostly concentrated between three- and four-year horizons. It should also be

\footnotetext{
${ }^{14}$ According to Baker et al. (2012), the US sentiment index contributes the most to the contagion of global sentiment. It should be noted that we do not perform a linear regression to generate a local sentiment index which is orthogonal to the global sentiment index, simply because multicolinearity is not a big concern here as China's local sentiment has very little correlation with the US sentiment.
} 
noted that the inclusion of the global sentiment also increase the explanatory power of the model as revealed by the increased $R^{2}$ values compared with their univariate counterparts (unreported). Overall, we confirm the findings in Baker et al. (2012) that sentiment spreads across markets and global sentiment is a contrarian predictor for country-level returns in the long run.

\section{Cross-sectional Analysis}

\subsection{Size-sorted Portfolios}

Although our main focus of the paper is on the aggregated market level, we also shed some light on the sentiment impact in the cross section during our sample period. Lee et al. (1991) contend that investor sentiment is more of a size story: Small firms are influenced more than large firms, which is later confirmed by other studies (Baker \& Wurgler 2006, 2007; Baker et al. 2012; Stambaugh et al. 2012).

Given the strong market power of retail investors in China, it makes sense to use market capitalization as a valid proxy for sentiment sensitivity, and to test the forecasting power of investor sentiment in the cross section. Accordingly, we sort stocks into large-, medium-, and small-cap portfolios based on empirical breakpoints of market capitalization at the 30th and 70th percentiles. That is, large-cap stocks represent sentiment immune stocks, while small-cap stocks represent sentiment-prone stocks. We should point out that if sentiment does impact more on small firms than large ones, we would expect to find that the short-term momentum signal is more pronounced for small firms, as those are the firms subject more to irrational sentiment, making it more difficult to arbitrage away sentiment-induced mispricing.

To establish the cross sectional effect of sentiment, we adopt the same predictive regression framework as in Equation [4.9], except that the dependent variables are replaced by the monthly excess return series of the three size-sorted portfolios and the return of a zero-cost portfolio, in which we go long the small-cap and short the big-cap portfolio. Again, we test the null hypothesis $\left(H_{0}: \beta=0\right)$ that investor sentiment has no predictive ability based on the significance of the slope coefficient. 
Figure 5 and 6 reports the $t$-statistics of the slope coefficient from the predictive regressions across different time horizons (one to 60 months), using the OLS and mARM estimation methods, respectively. Summarizing the two graphs, we observe a number of empirical patterns. First, it is reassured that (local) investor sentiment is a reliable momentum signal in the short run across the three size-sorted portfolios. Second, the short-term momentum effect seems to matter more for the small sized firms than for the large ones, as there are more significantly positive $t$-statistics within the first year. Besides, the slope coefficients on the size portfolios monotonically increase in magnitude from large-cap to small-cap stocks, while the $R^{2}$ values also rise monotonically (untabulated). Third, while market sentiment serves as a contrarian predictor in the long run, the negative impact gets weaker from large-cap to small-cap stocks. In other words, the strong positive time-series predictability is more pronounced and lasts over longer horizons for smallcap stocks than large-cap ones. Finally, and the most strikingly, we find the $t$-statistics on the slope coefficients for the regression using the zero-cost portfolio returns (as the dependent variable) are mostly positive during the 60-month forecasting horizons. That is, high sentiment implies a high size premium over future investment horizons. This striking cross-sectional difference goes counter to the existing findings of contrarian predictability regarding the sentiment effect from the developed markets. The bottom line, however, is that we confirm that sentiment is a size story. That is, it reinforces our conjecture that the momentum signal extracted from market sentiment is more pronounced for small firms than for large firms in China. Considering the strong short-sales constraints in China, it seems reasonable to argue that small firms are subject more to irrational sentimental beliefs and it is more difficult to arbitrage away sentiment-induced mispricing, compared with their large-cap counterparts.

Overall, we can conclude that the sentiment impact is stronger for small-sized stocks than for large-sized stocks, indicating that the price of small stocks exhibits possibly stronger run-up induced by retail investors over relatively long investment horizons.

\subsection{Cross-sectional Effect of Global Sentiment}

Following the cross-sectional analysis in the prior subsection, we check whether the impact of the global sentiment might also differ in the cross section. We adopt the same predictive regression framework with both local and global sentiment as in Equation [4.10], except that the dependent variables are now replaced by the monthly excess return series of the three size-sorted portfolios 
and the return of a zero-cost portfolio, in which we go long the small-cap and short the big-cap stocks. The sample period is restricted to July 1997 to December 2010 due to the limits of the data on global sentiment.

Figures 7 and 8 visualize the $t$-statistics of the slope coefficient on global sentiment, using the OLS and mARM estimation methods, respectively. Based on the two graphs, a number of empirical patterns can be summarized. First, comparing the plots on the three size-sorted portfolios, we find again that global sentiment does not have an immediate impact, but influence stock returns negatively in the long run across all the size groups. In particular, the long-run contrarian predictability is concentrated between three- and four-year horizons, confirming global sentiment spillover to the local markets as documented in (Baker et al. 2012).

Second, we evaluate whether there are any cross-sectional differences by checking the impact of the global sentiment on the zero-cost portfolio, in which we go long the small-cap stocks and short the large-cap ones. We find some (weak) evidence that global sentiment acts as a warning sign for the size premium in the long run as the $t$-statistics are mostly negative from the 13th month onwards. However, none of the $t$-statistics are significant at the conventional $5 \%$ level.

Overall, our finding reinforced the role of global sentiment, which spreads across markets and predicts negatively stock returns in the cross section.

\section{Discussion and Concluding Remarks}

This paper contributes to the growing literature on investor sentiment in financial markets. Our focus on the Chinese A-share market offers complementary evidence of sentiment effects from an emerging market perspective, for example, the dominant presence of retail investors, stringent short-sales constraints, heavy capital controls and less openness to the international investors. All of these features of an emerging market provide an important piece of "out-of-sample" evidence to gauge the forecasting power of investor sentiment at the market level and in the cross section.

In contrast to the prevailing view that (local) investor sentiment is a contrarian predictor of market returns at nearly all horizons, we find compelling evidence that (local) investor sentiment in China is a reliable momentum signal at the monthly frequency: A one-standard-deviation 
increase in sentiment translates into a (bias-adjusted) $1.50 \%$ rise in market excess returns per month, an economically significant result for all market participants. More strikingly, we document an interesting pattern that investor sentiment shifts from a momentum predictor in the short term (mainly within one year) to a long-run contrarian predictor in subsequent periods. Cross-sectional evidence reveals two things. First, it reinforces the conventional view that investor sentiment is more of a small-firm effect. Second, it suggests that the strong positive time-series predictability is more pronounced and lasts over longer horizons for small-cap stocks than large cap ones. In comparison, the impact of global sentiment is less immediate, but does predict returns negatively over longer horizons and in the cross section, confirming that the sentiment spills over from the global market.

The dramatic shift of investor sentiment from a short-term momentum predictor to a long-run warning sign implies two things. First, on average, (local) investor sentiment gets the future market direction correct over the short investor horizon. Second, despite the fact that systematic biased beliefs of uninformed investors can persist for an unexpectedly long period of time, it eventually leads to subsequent price reversals shown by the long-run contrarian predictability. From a broad perspective, the documented term structure of the sentiment effect and its associated pricing impact can help address a number of seemingly anomalous phenomena in China. One such example is the long-lasting price discrepancies between A-shares and B-shares in China (Mei et al. 2009), or the same Chinese firm being crossed-listed in the Chinese A-share markets and in the Hong Kong Stock Exchange or in NYSE/Nasdaq in the US (Chan et al. 2008). Another example is the IPO frenzy in China's primary market and its associated extreme IPO underpricing in the secondary market (Tian 2011). Therefore, the policy implication of our study is to further improve the short-selling mechanisms in China not only for large-cap stocks, but, more importantly, for small-cap stocks. 
Figure 1. Market Excess Returns and Investor Sentiment of the Entire Sample: 1997-2013

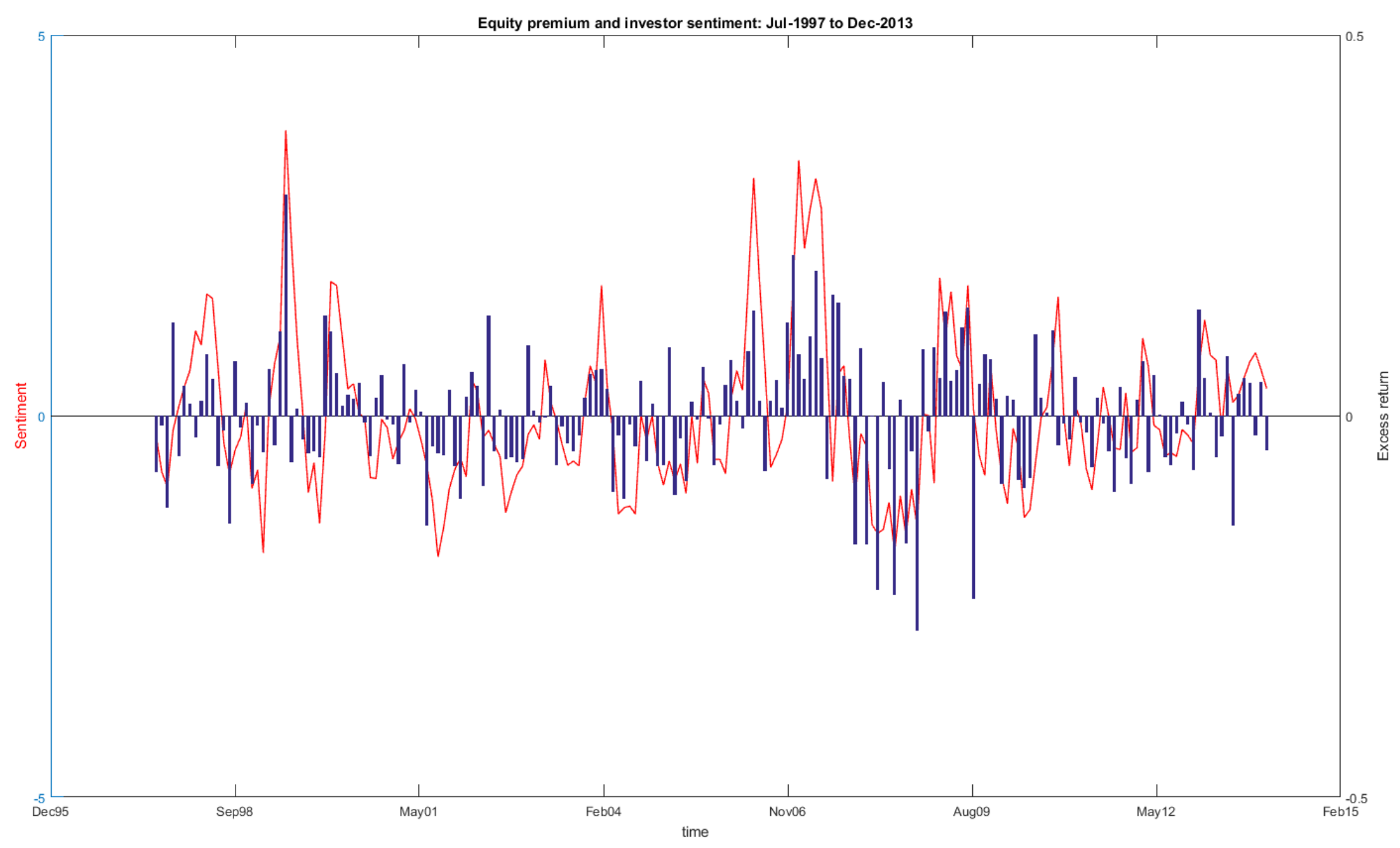

The solid line (the left y-axis) depicts the standardized investor sentiment index obtained from the principal component analysis, the PCA sentiment index. The solid bar (the right y-axis) depicts the (monthly) market excess return (in deciles) over the risk-free rate. The plot covers the entire sample period from July 1997 to December 2013. 
Figure 2. Multi-horizon Predictability Pattern under Alternative Estimation Methods.
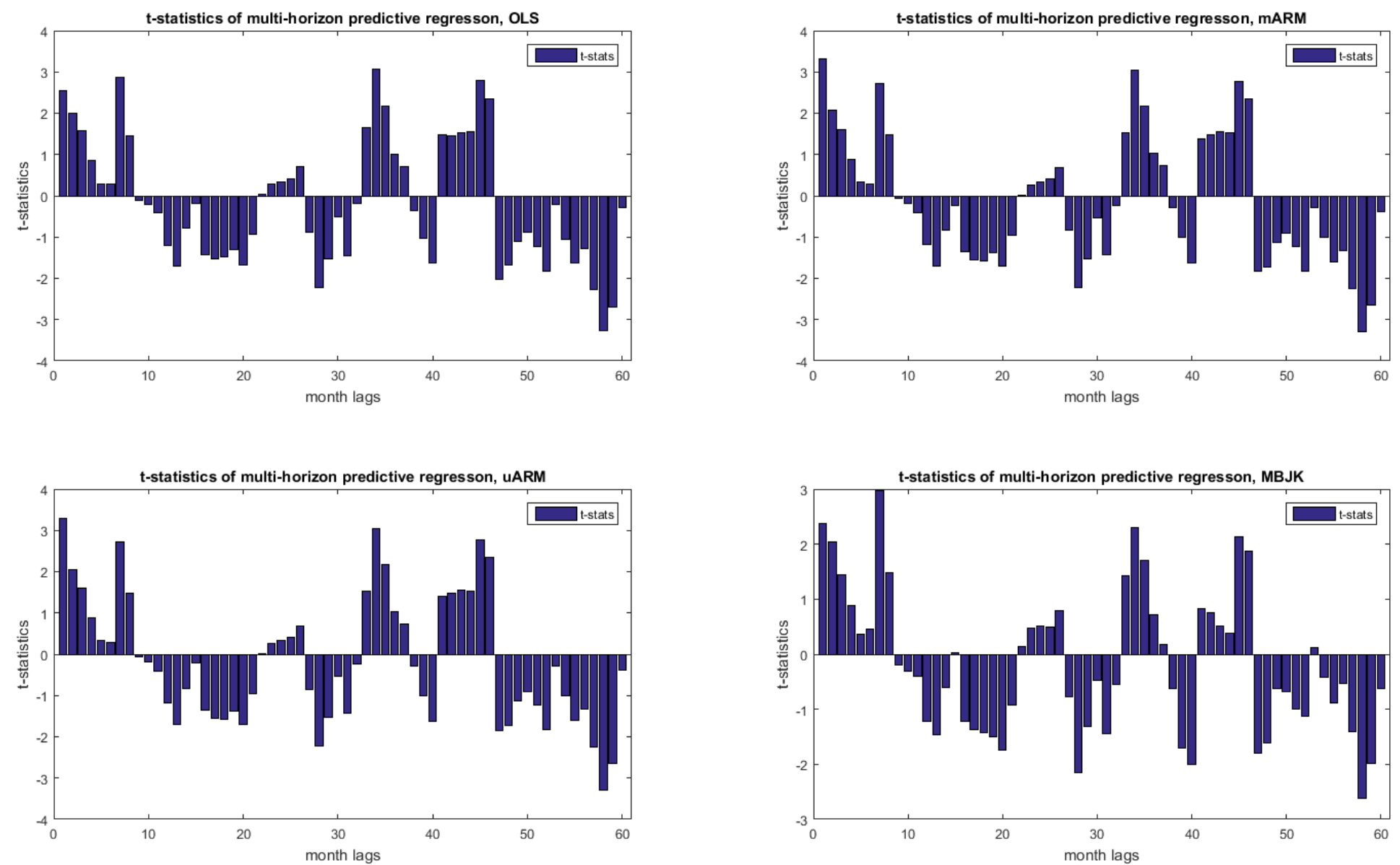

The figure depicts the $t$-statistics of the slope coefficients in the multi-horizon predictive regression under alternative estimation methods. Panel A to D represent the OLS, mARM, uARM, and MBJK methods, respectively. We regress the monthly excess return of the total market on the lagged sentiment index over various horizons. The horizons (month lags) vary from one month to 60 months. The plot is obtained from the entire sample period from July 1997 to December 2013. 
Figure 3. Local and Global Investor Sentiment during the Sample Period: 1997-2010

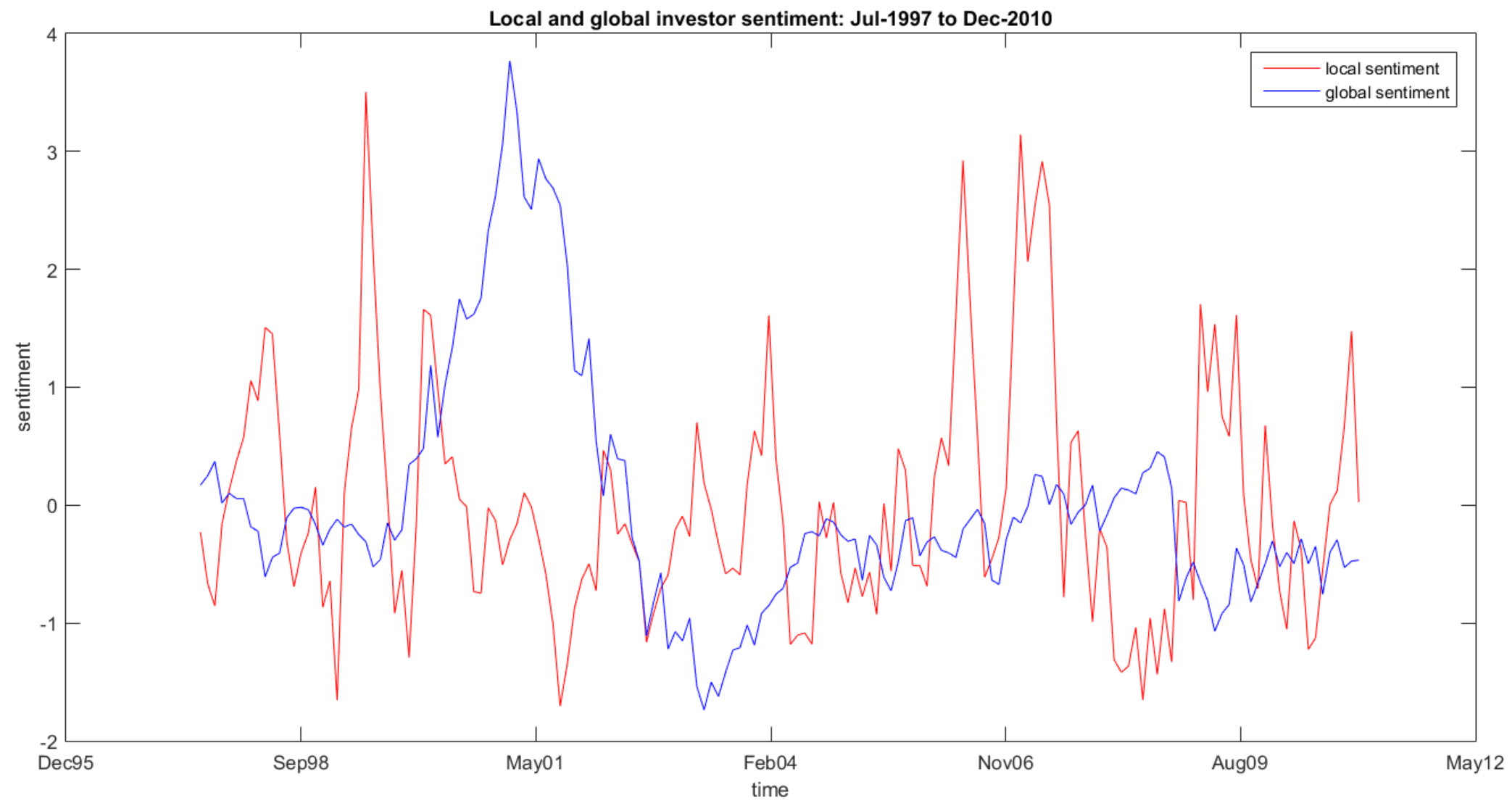

The red line depicts the local investor sentiment, proxied by the PCA sentiment index, while the blue line depicts the global sentiment, proxied by the US sentiment index by Baker and Wurgler (2006). Both time-series are re-standardized to have mean zero and unit variance during the common period from July 1997 to December 2010. 
Figure 4. Multi-horizon Predictability Patterns of the Local and Global Sentiment, OLS and mARM method
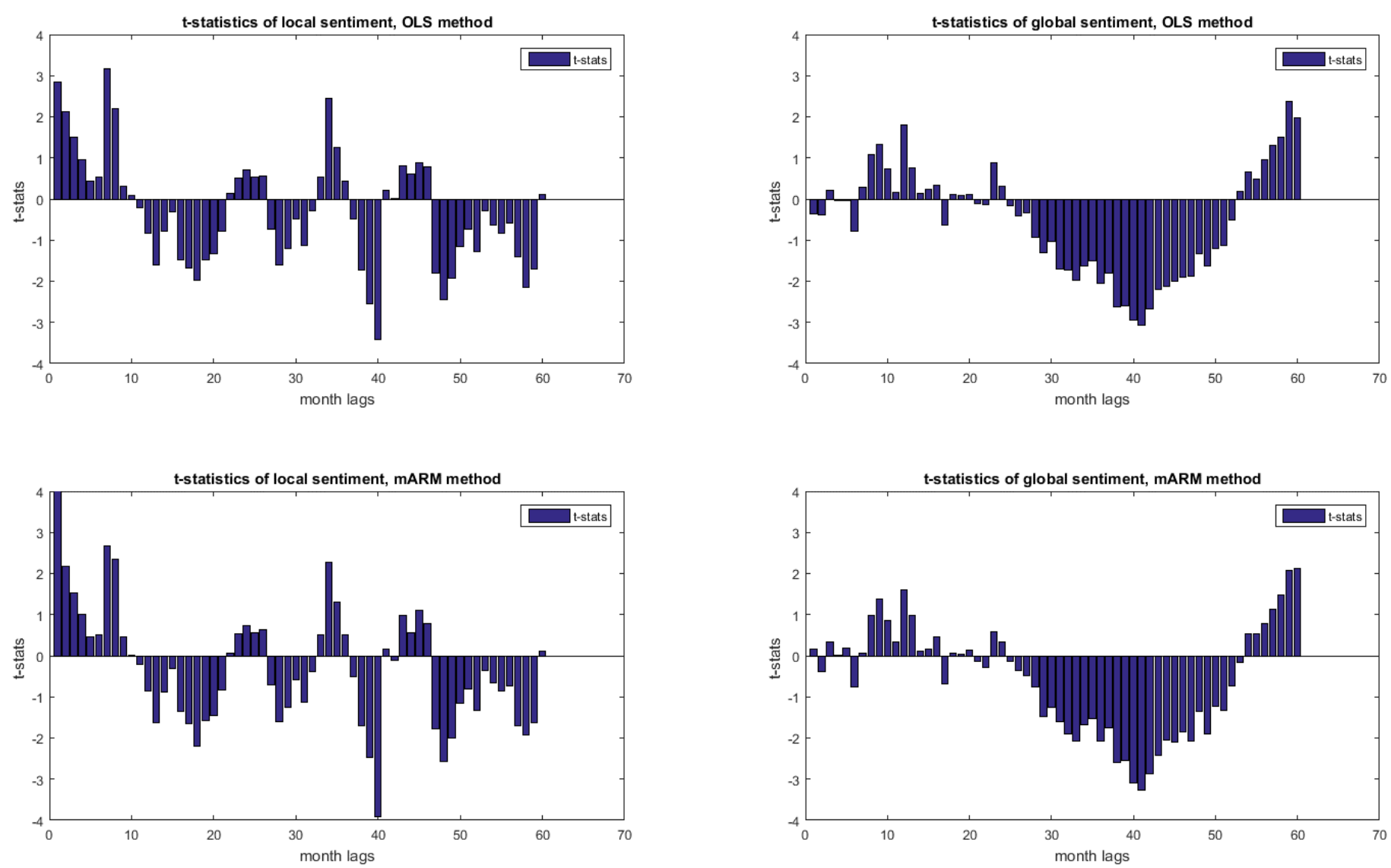

The figure depicts the $t$-statistics of the slope coefficients on the local and global sentiment indices, respectively. We use both OLS and mARM methods in the multi-horizon predictive regression. The horizons (month lags) vary from one month up to 60 months. The plot is obtained from the entire sample period from July 1997 to December 2013. 
Figure 5. Multi-horizon Predictability Patterns in the Cross Section, OLS Method
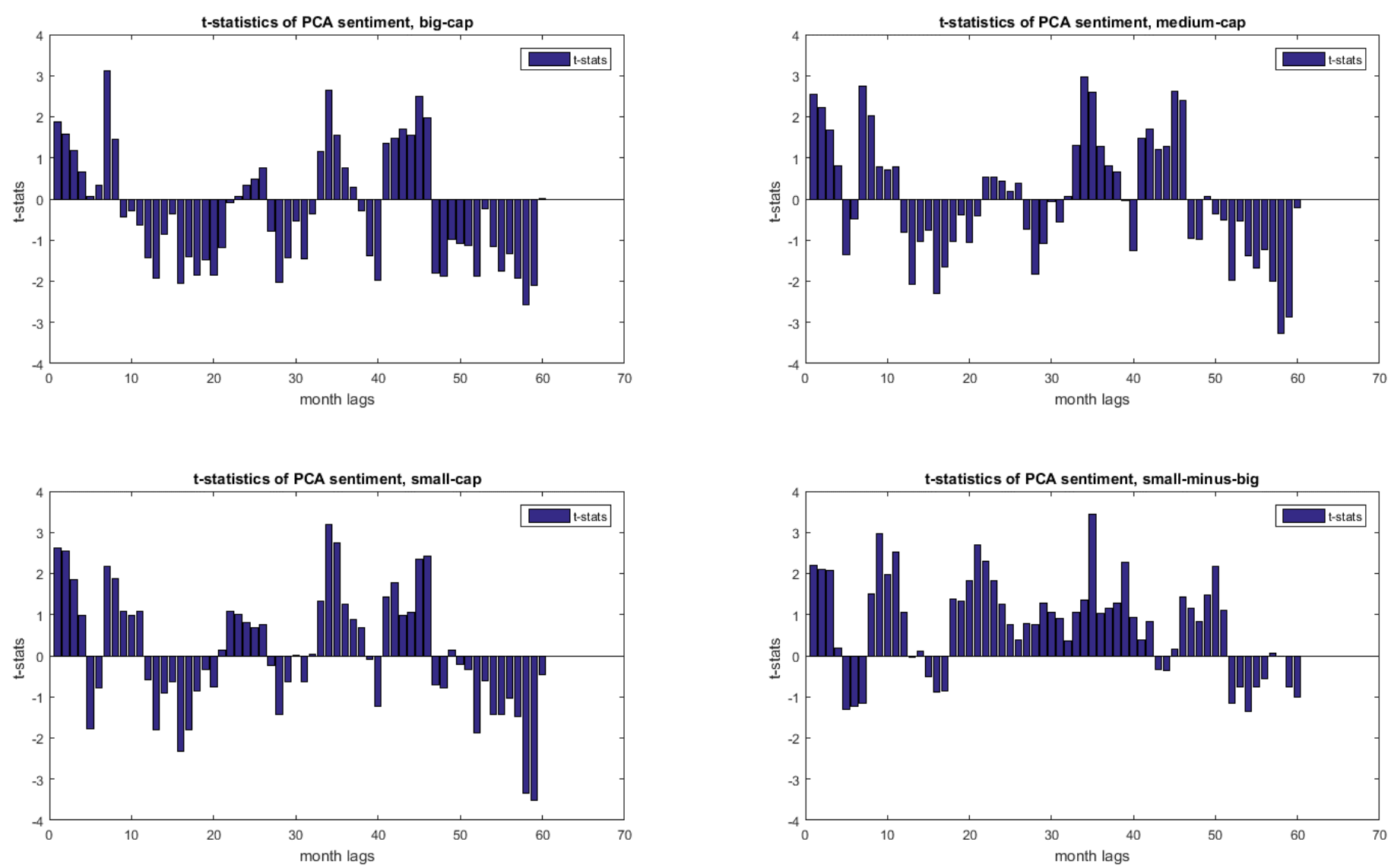

The figure depicts the $t$-statistics of the slope coefficient on the sentiment index in the multi-horizon predictive regression using the OLS method. We regress the monthly excess return of the big-cap, medium-cap, small-cap, and small-minus-big portfolio on the lagged sentiment index over various horizons. The horizons (month lags) vary from one month up to 60 months. The plot is obtained from the entire sample period from July 1997 to December 2013. 
Figure 6. Multi-horizon Predictability Patterns in the Cross Section, mARM method
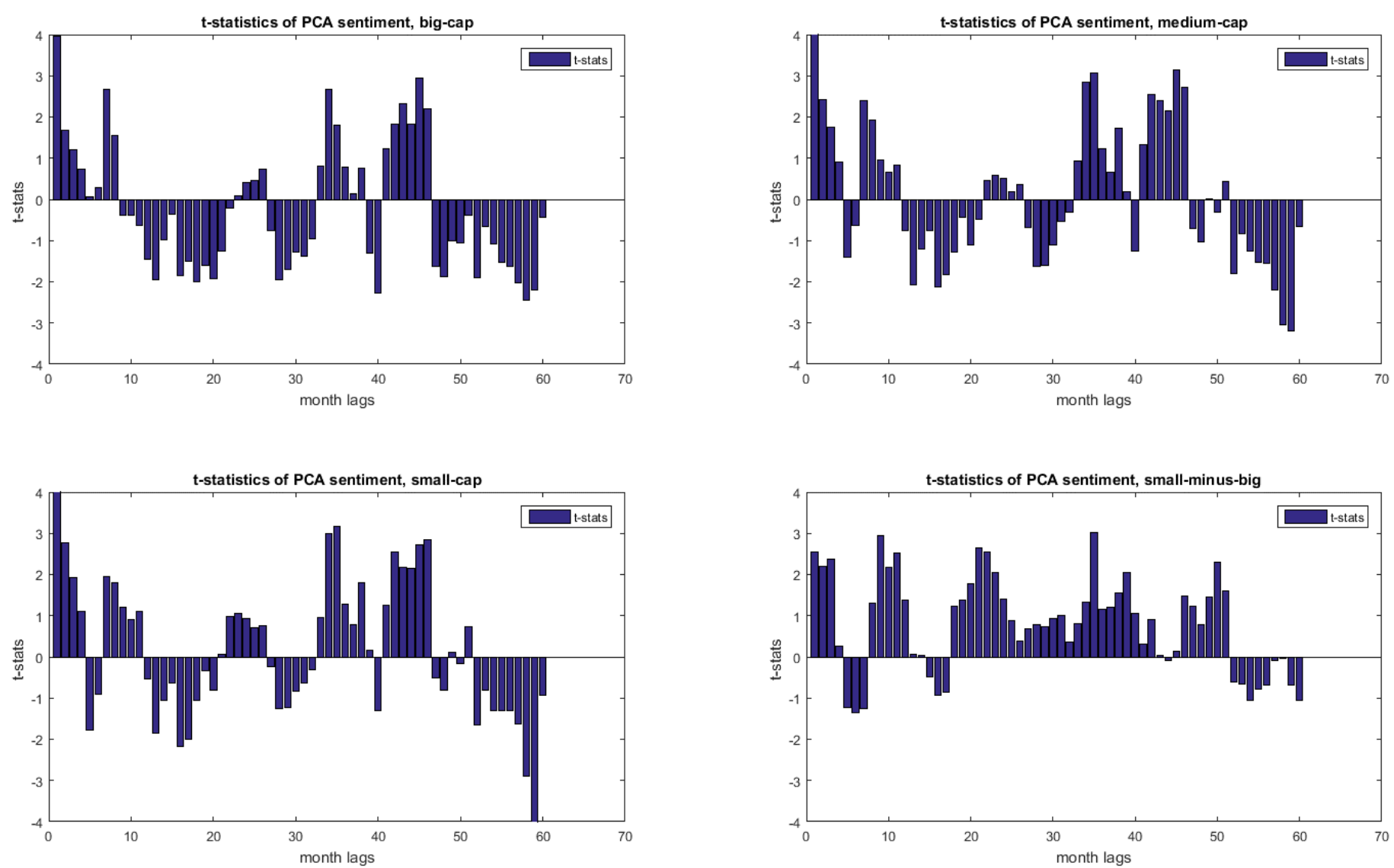

The figure depicts the $t$-statistics of the slope coefficient on the sentiment index in the multi-horizon predictive regression using the mARM method. We regress the monthly excess return of the big-cap, medium-cap, small-cap, and small-minus-big portfolio on the lagged sentiment index over various horizons. The horizons (month lags) vary from one month up to 60 months. The plot is obtained from the entire sample period from July 1997 to December 2013. 
Figure 7. Multi-horizon Predictability Patterns of the Global Sentiment for the Size-sorted Portfolios, OLS method
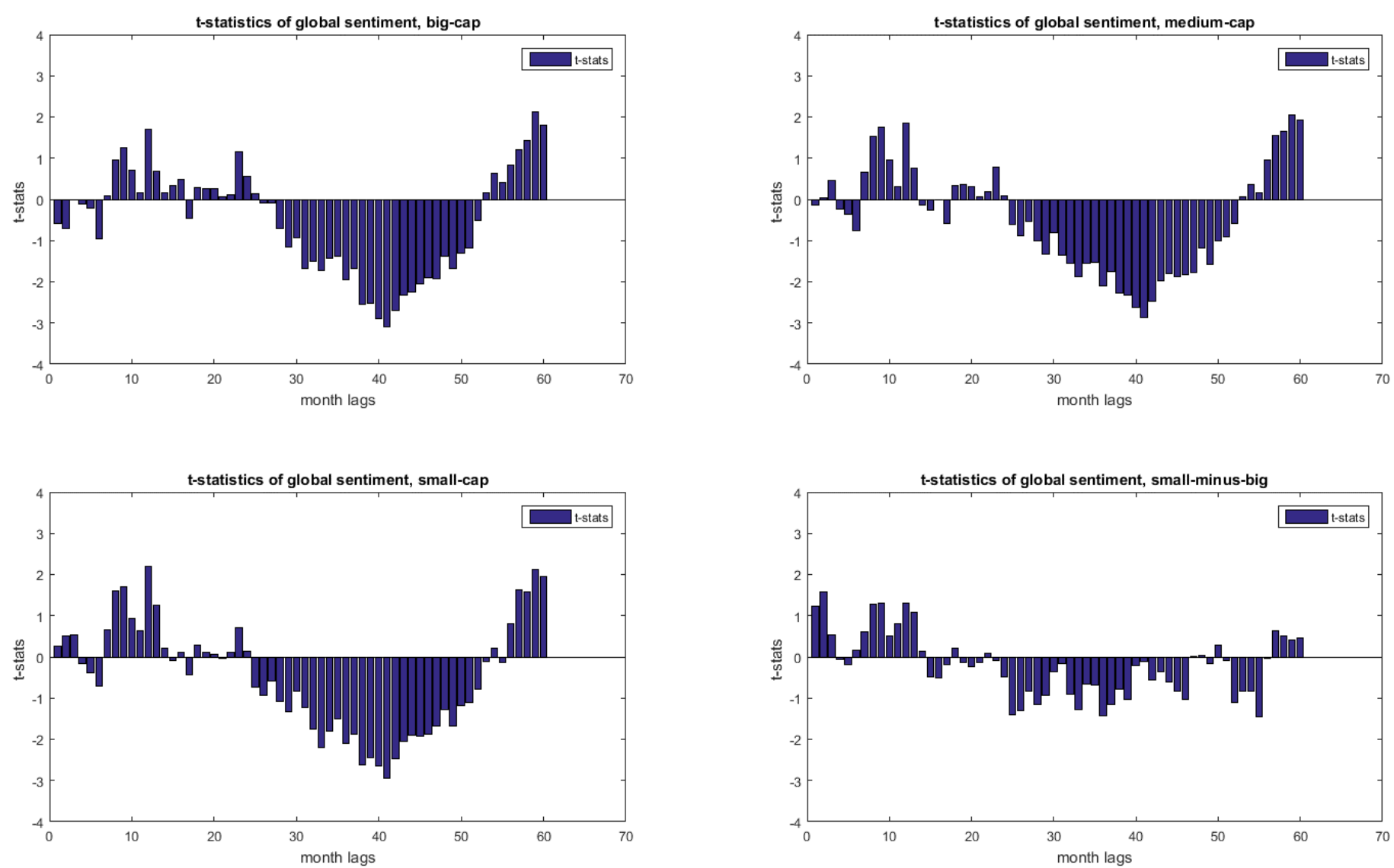

The figure depicts the $t$-statistics of the slope coefficients on the global sentiment index in the multi-horizon predictive regression using the OLS method. We regress the monthly excess return of the big-cap, medium-cap, small-cap, and small-minus-big portfolio on the lagged local and global sentiment indexes over various horizons. The horizons (month lags) vary from one month up to 60 months. The plot is obtained from the entire sample period from July 1997 to December 2013. 
Figure 8. Multi-horizon Predictability Patterns of the Global Sentiment for the Size-sorted Portfolios, mARM method
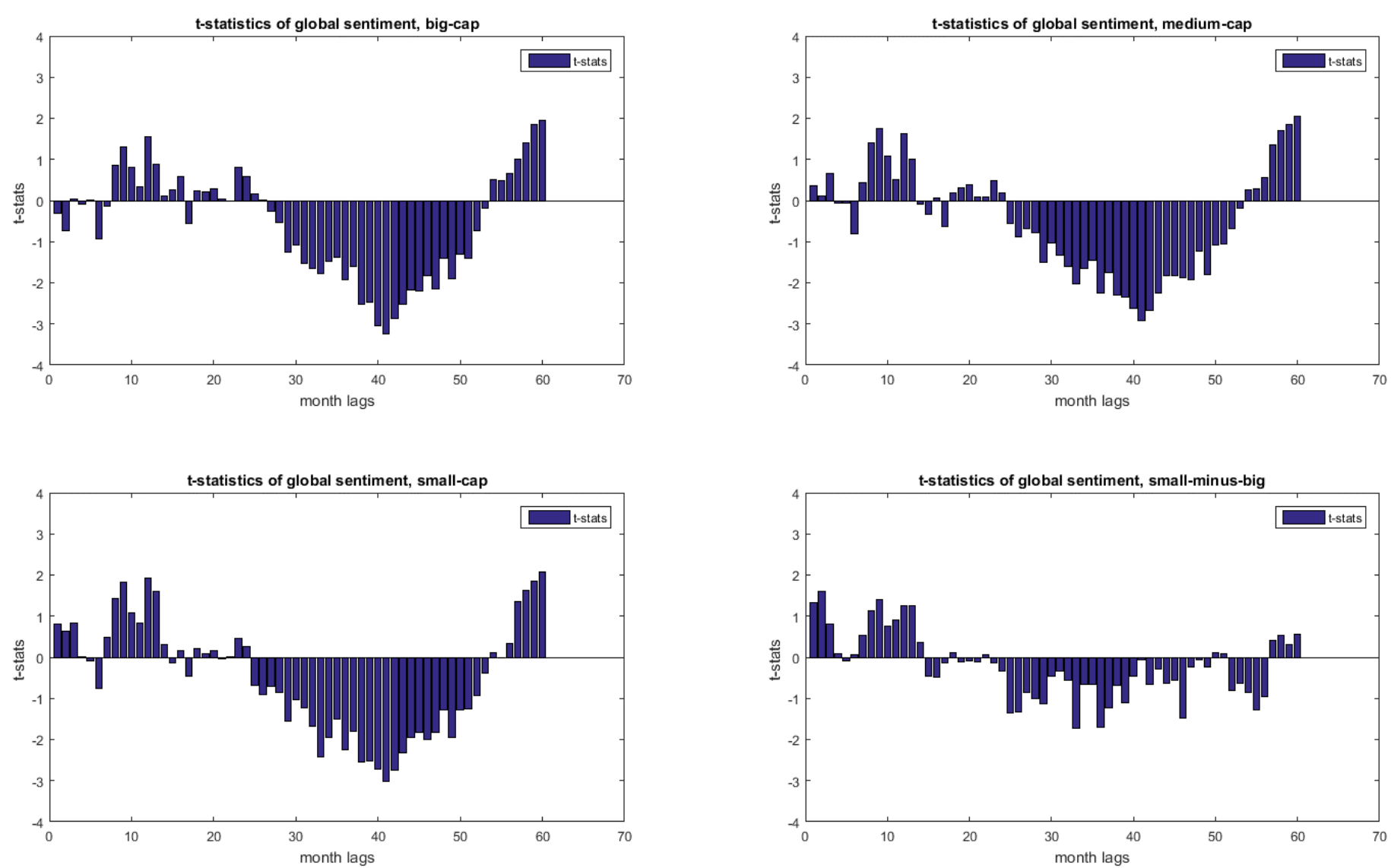

The figure depicts the $t$-statistics of the slope coefficients on the global sentiment index in the multi-horizon predictive regression using the mARM method. We regress the monthly excess return of the big-cap, medium-cap, small-cap, and small-minus-big portfolio on the lagged local and global sentiment indexes over various horizons. The horizons (month lags) vary from one month up to 60 months. The plot is obtained from the entire sample period from July 1997 to December 2013. 


\section{Table 1: Data and Data Sources}

\begin{tabular}{|l|l|}
\hline Variables & Sources \\
\hline $\begin{array}{l}\text { Market capitalization (MV), Monthly return (Ret), Daily turnover } \\
\text { (Turn), One-year time deposit rate (RF), }\end{array}$ & Thomson Reuters Datastream \\
\hline $\begin{array}{l}\text { Business cycle indicator (BCI), Industrial production (IP), Number of } \\
\text { new opened individual investor accounts in Shanghai Stock Exchange } \\
\text { (IIA), Money supply (M2), 30-day National interbank offer rate (IR), } \\
\text { Exchange rate (CNY/USD), Consumer confidence index (CCI) }\end{array}$ & \\
\hline Market-wide PE ratio (PE) & CICC database \\
\hline US sentiment index & $\underline{\text { Baker and Wurgler (2007) }}$ \\
\hline
\end{tabular}




\section{Table 2: Descriptive Statistics}

In this table, we present the summary statistics for the monthly excess return of the market portfolio $\left(\operatorname{Ret}_{t}\right)$, sentiment index constructed by principal component analysis $\left(S_{t}^{P C A}\right)$, the three composite sentiment proxies (all orthogonalized to macro effects): Turnover ratio $\left(T U R N_{t}^{O}\right)$, the number of newly opened investor accounts in Shanghai Stock Exchange $\left(I I A_{t}^{O}\right)$, and the value-weighted PE ratio $\left(P E_{t}^{O}\right)$. The business cycle indicator $\left(B C I_{t}\right)$, the growth of the industrial production $\left(I P_{t}\right)$, and the market-wide PE ratio $\left(P E_{t}\right)$. The upper part of the table reports the arithmetic mean, median, standard deviation, skewness, kurtosis, minimum, maximum, $25 \%$ and $75 \%$ quantile points, and first order autocorrelation coefficient, while the lower part the cross-correlation coefficients. The sample period is from July 1997 to December 2013.

\begin{tabular}{crrrrrrrrrrr}
\hline & Obs. & Mean & Median & St.Dev. & Min & Max & Skew & Kurt & 25\% & 75\% & Rho \\
\hline Ret $_{t}(\%)$ & 198 & 0.16 & 0.24 & 8.07 & -28.11 & 29.03 & -0.18 & 4.39 & -5.19 & 4.91 & 0.04 \\
$S_{t}^{P C A}$ & 198 & 0.00 & -0.18 & 1 & -1.85 & 3.75 & 1.06 & 4.58 & -0.65 & 0.55 & 0.70 \\
$T U R N_{t}^{O}$ & 198 & 0.00 & -0.15 & 1 & -2.77 & 3.19 & 0.77 & 4.37 & -0.68 & 0.56 & 0.56 \\
$I I A_{t}^{O}$ & 198 & 0.00 & -0.13 & 1 & -2.94 & 3.35 & 0.91 & 4.78 & -0.63 & 0.46 & 0.63 \\
$P E_{t}^{O}$ & 198 & 0.00 & 0.01 & 1 & -3.12 & 2.55 & -0.35 & 3.93 & -0.51 & 0.59 & 0.83 \\
$C C I_{t}$ & 198 & 0.00 & 0.26 & 1 & -2.39 & 1.45 & -0.52 & 2.23 & -0.81 & 0.79 & 0.92 \\
$B C I_{t}$ & 198 & 0.00 & 0.15 & 1 & -2.42 & 1.76 & -0.44 & 2.52 & -0.61 & 0.74 & 0.97 \\
$I P_{t}$ & 198 & 0.00 & -0.03 & 1 & -2.89 & 2.66 & -0.10 & 2.69 & -0.81 & 0.80 & 0.58 \\
$P E_{t}$ & 198 & 0.00 & 0.12 & 1 & -1.93 & 1.69 & -0.28 & 1.85 & -0.94 & 0.81 & 0.98 \\
& & & & & & & & & & & \\
& $R e t_{t}$ & $S_{t}^{P C A}$ & $T U R N_{t}^{O}$ & $I I A_{t}^{O}$ & $P E_{t}^{O}$ & $C C I_{t}$ & $B C I_{t}$ & $I P_{t}$ & $P E_{t}$ & & \\
$\operatorname{Rt}_{t}$ & 1 & 0.55 & 0.43 & 0.35 & 0.59 & 0.02 & -0.05 & -0.03 & 0.14 & & \\
$S_{t}^{P C A}$ & 0.55 & 1 & 0.80 & 0.90 & 0.72 & -0.10 & -0.12 & -0.01 & 0.07 & & \\
$T U R N_{t}^{O}$ & 0.43 & 0.80 & 1 & 0.63 & 0.29 & -0.15 & -0.12 & -0.03 & -0.17 & & \\
$I I A_{t}^{O}$ & 0.35 & 0.90 & 0.63 & 1 & 0.52 & -0.04 & -0.09 & 0.00 & 0.09 & & \\
$P E_{t}^{O}$ & 0.59 & 0.72 & 0.29 & 0.52 & 1 & -0.07 & -0.08 & 0.02 & 0.26 & & \\
$C C I_{t}$ & 0.02 & -0.10 & -0.15 & -0.04 & -0.07 & 1 & 0.16 & 0.28 & 0.66 & & \\
$B C I_{t}$ & -0.05 & -0.12 & -0.12 & -0.09 & -0.08 & 0.16 & 1 & 0.67 & -0.09 & & \\
$I P_{t}$ & -0.03 & -0.01 & -0.03 & 0.00 & 0.02 & 0.28 & 0.67 & 1 & 0.09 & & \\
$P E_{t}$ & 0.14 & 0.07 & -0.17 & 0.09 & 0.26 & 0.66 & -0.09 & 0.09 & 1 & & \\
\hline & & & & & & & & & &
\end{tabular}




\section{Table 3. Single-factor Predictive Regression}

The table reports the estimation results of the predictive regression with single regressor. Panel A considers the PCA sentiment index for the entire sample period and two subsample periods. Panel B considers the three individual sentiment composites (all orthogonalized to macro effects): Turnover ratio $\left(T U R N_{t}^{O}\right.$ ), the number of newly opened investor accounts in Shanghai Stock Exchange $\left(I I A_{t}^{O}\right)$, and the value-weighted PE ratio $\left(P E_{t}^{O}\right)$. Panel $\mathrm{C}$ considers three alternative sentiment indexes. The first one is the equal-weighted naïve sentiment index (denoted as $S_{t}^{\text {Naive }}$ ), the second is the PCA sentiment index excluding $P E_{t}^{O}$ as a component (denoted as $S_{t}^{E x P E}$ ), and the third one uses consumer confidence index $\left(C C I_{t}\right)$, a survey-based index. For each predictor variable, we report the slope coefficients obtained from both the OLS method (first line) and the mARM method (second line). *, **, and *** stand for significance at the $10 \%, 5 \%$ and $1 \%$ level, based on Newey-West $t$-statistics.

\begin{tabular}{|c|c|c|c|c|c|}
\hline & Beta & $t$-stat & $p$-value & Empirical $p$-value & $R^{2}$ \\
\hline & \multicolumn{5}{|c|}{ Panel A: PCA sentiment index, entire sample } \\
\hline OLS & $0.0138 * *$ & 2.55 & 0.0115 & 0.0150 & $2.95 \%$ \\
\hline \multirow[t]{2}{*}{ mARM } & $0.0150 * * *$ & 3.32 & 0.0011 & 0.0135 & $38.98 \%$ \\
\hline & \multicolumn{5}{|c|}{ Subsample 1: July 1997-December 2005} \\
\hline OLS & $0.0089 * *$ & 2.42 & 0.0174 & 0.0375 & $1.73 \%$ \\
\hline \multirow[t]{2}{*}{ mARM } & $0.0112 * * *$ & 3.25 & 0.0016 & 0.0980 & $47.52 \%$ \\
\hline & \multicolumn{5}{|c|}{ Subsample 2: January 2006-December 2013} \\
\hline OLS & $0.0169 *$ & 1.90 & 0.0608 & 0.0480 & $3.44 \%$ \\
\hline \multirow[t]{2}{*}{ mARM } & $0.0194 * *$ & 2.52 & 0.0133 & 0.0320 & $34.57 \%$ \\
\hline & \multicolumn{5}{|c|}{ Panel B: Individual composites of sentiment index, entire sample } \\
\hline \multicolumn{6}{|c|}{ 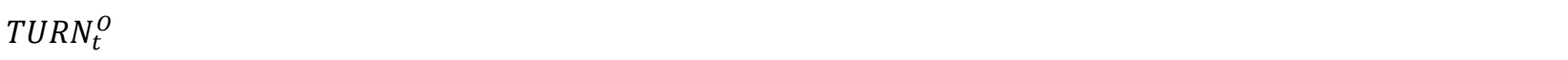 } \\
\hline OLS & $0.0085 * *$ & 2.18 & 0.0303 & 0.0295 & $1.10 \%$ \\
\hline mARM & $0.0091 * *$ & 2.39 & 0.0178 & 0.0790 & $20.59 \%$ \\
\hline \multicolumn{6}{|l|}{$I I A_{t}^{O}$} \\
\hline OLS & 0.0105 & 1.61 & 0.1100 & 0.0800 & $1.70 \%$ \\
\hline mARM & $0.0111^{*}$ & 1.87 & 0.0636 & 0.0480 & $13.99 \%$ \\
\hline \multicolumn{6}{|l|}{$P E_{t}^{O}$} \\
\hline OLS & $0.0154 * * *$ & 3.15 & 0.0019 & 0.0050 & $3.64 \%$ \\
\hline \multirow[t]{2}{*}{ mARM } & $0.0177 * * *$ & 5.69 & 0.0000 & 0.0065 & $64.40 \%$ \\
\hline & \multicolumn{5}{|c|}{ Panel C: Alternative sentiment index, entire sample } \\
\hline \multicolumn{6}{|l|}{$S_{t}^{\text {Naive }}$} \\
\hline OLS & $0.0141 * * *$ & 2.63 & 0.0092 & 0.0170 & $2.59 \%$ \\
\hline mARM & $0.0153 * * *$ & 3.55 & 0.0005 & 0.0125 & $41.15 \%$ \\
\hline \multicolumn{6}{|l|}{$S_{t}^{E x P E}$} \\
\hline OLS & $0.0105^{* *}$ & 2.19 & 0.0295 & 0.0340 & $1.70 \%$ \\
\hline mARM & $0.0112 * *$ & 2.42 & 0.0165 & 0.0525 & $21.54 \%$ \\
\hline \multicolumn{6}{|l|}{$C C I_{t}$} \\
\hline OLS & -0.0003 & -0.05 & 0.9615 & 0.9900 & $0.00 \%$ \\
\hline mARM & 0.0003 & 0.04 & 0.9651 & 0.8900 & $0.35 \%$ \\
\hline
\end{tabular}




\section{Table 4. Multiple-factor Predictive Regression}

The table reports the output of the multi-variate predictive regressions under alternative model specifications. Specification 1 to 3 are bivariate predictive regressions which estimate the sentiment effect while controlling for the effect of business cycle $\left(B C I_{t}\right)$, the growth of the industrial production $\left(I P_{t}\right)$, and the market-wide PE ratio $\left(P E_{t}\right)$. Specification 4 is the kitchen sink model which includes all the three control variables simultaneously. For brevity, we report only the slope coefficients estimated from the mARM method. *, **, and *** stand for significance at the $10 \%, 5 \%$ and $1 \%$ level, based on Newey-West $t$-statistics.

\begin{tabular}{|c|c|c|c|c|c|}
\hline$m A R M$ & Beta & $t$-stat & $p$-value & Empirical $p$-value & $\overline{R^{2}}$ \\
\hline \multicolumn{6}{|c|}{ Specification 1} \\
\hline$S_{t}^{P C A}$ & $0.0144 * * *$ & 3.67 & 0.0003 & 0.0115 & $40.11 \%$ \\
\hline$B C I_{t}$ & 0.0000 & 0.01 & 0.9883 & 0.4890 & \\
\hline \multicolumn{6}{|c|}{ Specification 2} \\
\hline$S_{t}^{P C A}$ & $0.0152 * * *$ & 3.23 & 0.0015 & 0.0115 & $40.80 \%$ \\
\hline$I P_{t}$ & 0.0006 & 0.16 & 0.8763 & 0.4875 & \\
\hline \multicolumn{6}{|c|}{ Specification 3} \\
\hline$S_{t}^{P C A}$ & $0.0134 * * *$ & 4.30 & 0.0000 & 0.0235 & $76.49 \%$ \\
\hline$P E_{t}$ & $0.0041 * *$ & 2.12 & 0.0349 & 0.0310 & \\
\hline \multicolumn{6}{|c|}{ Specification 4} \\
\hline$S_{t}^{P C A}$ & $0.0139 * * *$ & 4.95 & 0.0000 & 0.0230 & $77.16 \%$ \\
\hline$B C I_{t}$ & -0.0018 & -1.06 & 0.2922 & 0.8180 & \\
\hline$I P_{t}$ & $-0.0057^{*}$ & -1.80 & 0.0736 & 0.3565 & \\
\hline$P E_{t}$ & $0.0099 * * *$ & 3.01 & 0.0030 & 0.1385 & \\
\hline
\end{tabular}




\section{Table 5. Out-of-sample Forecast Performance}

The table reports the out-of-sample performance of various predictors in predicting subsequent market returns. The out-of-sample forecasts are formed using fitted valued of the slope coefficients from OLS, mARM, uARM, and MBJK estimation methods, respectively. Panel A considers the case of univariate predictive regression with either the PCA sentiment index or the naïve (equal-weighted) sentiment index as the predicting variable. Panel B considers the bivariate case with the PCA sentiment as one of the predictors, and another control variable as Business cycle indicator $\left(B C I_{t}\right)$, growth of industrial production $\left(I P_{t}\right)$, and $\mathrm{PE}$ ratio $\left(P E_{t}\right)$, respectively. All of the sentiment variables and model parameters are estimated recursively based on information prior to the forecast period. $R_{O S}^{2}$ is the Campbell and Thompson (2008) out-of-sample $R^{2}$, MSFE is the mean squared forecast error, DM-test is the Diebold and Mariano (1995) test statistic, and CW-test is the Clark and West (2007) MSFE-adjusted statistic. *, **, and $* * *$ stand for significance at the $10 \%, 5 \%$ and $1 \%$ level. The out-of-sample period ranges from January 2007 to December 2013.

\begin{tabular}{|c|c|c|c|c|}
\hline Method (Variables) & MSFE & $R_{O S}^{2}$ & DM-test & CW-test \\
\hline \multicolumn{5}{|c|}{ Panel A: Univariate Predictive Regression } \\
\hline $\operatorname{OLS}\left(S_{t}^{P C A}\right)$ & 0.00849 & $3.45 \%$ & 0.79 & $1.33 *$ \\
\hline $\operatorname{mARM}\left(S_{t}^{P C A}\right)$ & 0.00845 & $3.89 \%$ & 0,79 & $1.39 *$ \\
\hline $\mathrm{uARM}\left(S_{t}^{P C A}\right)$ & 0.00846 & $3.82 \%$ & 0,79 & $1.38 *$ \\
\hline $\operatorname{MBJK}\left(S_{t}^{P C A}\right)$ & 0.00851 & $3.25 \%$ & 0,70 & $1.29 *$ \\
\hline $\operatorname{OLS}\left(S_{t}^{\text {Naive }}\right)$ & 0.00848 & $3.54 \%$ & 0.78 & $1.35^{*}$ \\
\hline $\mathrm{mARM}\left(S_{t}^{\text {Naive }}\right)$ & 0.00845 & $3.96 \%$ & 0.78 & $1.41 *$ \\
\hline $\mathrm{uARM}\left(S_{t}^{\text {Naive }}\right)$ & 0.00845 & $3.90 \%$ & 0.78 & $1.40 *$ \\
\hline $\operatorname{MBJK}\left(S_{t}^{\text {Naive }}\right)$ & 0.00850 & $3.34 \%$ & 0.70 & $1.31 *$ \\
\hline \multicolumn{5}{|c|}{ Panel B: Bivariate Predictive Regression } \\
\hline $\mathrm{OLS}\left(S_{t}^{P C A}, B C I_{t}\right)$ & $\mathbf{0 . 0 0 8 5 0}$ & $3.40 \%$ & 0.77 & $1.39 *$ \\
\hline $\operatorname{mARM}\left(S_{t}^{P C A}, B C I_{t}\right)$ & 0.00863 & $1.84 \%$ & 0.37 & 1.23 \\
\hline $\mathrm{uARM}\left(S_{t}^{P C A}, B C I_{t}\right)$ & 0.00860 & $2.25 \%$ & 0.50 & 1.11 \\
\hline $\operatorname{MBJK}\left(S_{t}^{P C A}, B C I_{t}\right)$ & 0.00855 & $2.83 \%$ & 0.60 & $1.28 *$ \\
\hline $\operatorname{OLS}\left(S_{t}^{P C A}, I P_{t}\right)$ & 0.00856 & $2.67 \%$ & 0.62 & 1.21 \\
\hline $\operatorname{mARM}\left(S_{t}^{P C A}, I P_{t}\right)$ & 0.00852 & $3.12 \%$ & 0.64 & $1.29 *$ \\
\hline $\operatorname{mARM}\left(S_{t}^{P C A}, I P_{t}\right)$ & 0.00862 & $1.99 \%$ & 0.42 & 1.08 \\
\hline $\operatorname{MBJK}\left(S_{t}^{P C A}, I P_{t}\right)$ & 0.00856 & $2.69 \%$ & 0.57 & 1.22 \\
\hline $\operatorname{OLS}\left(S_{t}^{P C A}, P E_{t}\right)$ & 0.00868 & $1.28 \%$ & 0.27 & 0.97 \\
\hline $\operatorname{mARM}\left(S_{t}^{P C A}, P E_{t}\right)$ & 0.00856 & $2.63 \%$ & 0.51 & $1.37 *$ \\
\hline $\operatorname{mARM}\left(S_{t}^{P C A}, P E_{t}\right)$ & 0.00863 & $1.84 \%$ & 0.60 & 1.06 \\
\hline $\operatorname{MBJK}\left(S_{t}^{P C A}, P E_{t}\right)$ & 0.00868 & $1.34 \%$ & 0.29 & 0.93 \\
\hline
\end{tabular}




\section{Table 6. Trading Strategies}

Panel A and B reports the annualized mean returns and Sharpe ratios, respectively, for the buy-and-hold strategy (denoted as $\mathrm{B} \& \mathrm{H}$ ) and the long-only market timing strategy using different buy signals. $S_{t}^{P C A}$ denotes the timing strategy based on the buy signal when the lagged sentiment is above zero. OLS $\left(S_{t}^{P C A}\right), \operatorname{mARM}\left(S_{t}^{P C A}\right)$, mARM $\left(S_{t}^{P C A}\right)$, and MBJK $\left(S_{t}^{P C A}\right)$ denote the buy signals when the predicted excess return generated by the different estimation techniques (OLS, mARM, uARM, and MBJK) are above zero, respectively. TSMOM denotes the longonly time-series momentum strategy with the buy signal when the lagged twelve-month return (excluding the most recent month) exceeds zero. Panel C reports the Fama-French four-factor model regression results for the time-series momentum strategy and the timing strategy using the buy signal when the lagged sentiment is above zero. The outof-sample evaluation period is from January 2007 to December 2013.*,**, and *** stand for significance at the $10 \%, 5 \%$ and $1 \%$ level.

\begin{tabular}{|c|c|c|c|c|c|c|c|c|c|c|c|c|}
\hline \multicolumn{13}{|c|}{ Panel A: Annualized Mean Return (\%) } \\
\hline Holding period $=$ & 1 & 2 & 3 & 4 & 5 & 6 & 7 & 8 & 9 & 10 & 11 & 12 \\
\hline $\mathrm{B} \& \mathrm{H}$ & -1.40 & - & - & - & - & - & - & - & - & - & - & - \\
\hline$S_{t}^{P C A}$ & 10.75 & 12.59 & 13.30 & 12.84 & 11.13 & 10.27 & 10.04 & 9.54 & 7.69 & 6.88 & 6.34 & 5.04 \\
\hline $\operatorname{OLS}\left(S_{t}^{P C A}\right)$ & 4.75 & 7.92 & 8.13 & 9.25 & 6.81 & 6.27 & 6.40 & 5.48 & 3.59 & 2.63 & 2.57 & 1.30 \\
\hline $\operatorname{mARM}\left(S_{t}^{P C A}\right)$ & 5.95 & 10.81 & 10.24 & 10.70 & 8.57 & 7.68 & 7.72 & 6.79 & 5.21 & 4.01 & 3.78 & 2.31 \\
\hline $\mathrm{uARM}\left(S_{t}^{P C A}\right)$ & 5.95 & 10.81 & 10.24 & 10.70 & 8.57 & 7.68 & 7.72 & 6.79 & 5.21 & 4.01 & 3.78 & 2.31 \\
\hline $\operatorname{MBJK}\left(S_{t}^{P C A}\right)$ & 4.75 & 7.92 & 8.13 & 9.25 & 6.81 & 6.27 & 6.40 & 5.48 & 3.59 & 2.63 & 2.57 & 1.30 \\
\hline TSMOM & 0.11 & 3.12 & 1.00 & -0.29 & -0.70 & -0.98 & -2.02 & -2.54 & -2.85 & -2.82 & -2.90 & -2.84 \\
\hline \multicolumn{13}{|c|}{ Panel B: Annualized Sharpe Ratio } \\
\hline Holding period = & 1 & 2 & 3 & 4 & 5 & 6 & 7 & 8 & 9 & 10 & 11 & 12 \\
\hline $\mathrm{B} \& \mathrm{H}$ & -0.04 & - & - & - & - & - & - & - & - & - & - & - \\
\hline$S_{t}^{P C A}$ & 0.52 & 0.64 & 0.67 & 0.65 & 0.56 & 0.52 & 0.52 & 0.50 & 0.40 & 0.36 & 0.33 & 0.27 \\
\hline $\operatorname{OLS}\left(S_{t}^{P C A}\right)$ & 0.21 & 0.37 & 0.37 & 0.44 & 0.32 & 0.29 & 0.30 & 0.26 & 0.17 & 0.12 & 0.12 & 0.06 \\
\hline $\operatorname{mARM}\left(S_{t}^{P C A}\right)$ & 0.26 & 0.52 & 0.48 & 0.51 & 0.41 & 0.37 & 0.38 & 0.33 & 0.25 & 0.20 & 0.19 & 0.11 \\
\hline $\mathrm{uARM}\left(S_{t}^{P C A}\right)$ & 0.26 & 0.52 & 0.48 & 0.51 & 0.41 & 0.37 & 0.38 & 0.33 & 0.25 & 0.20 & 0.19 & 0.11 \\
\hline $\operatorname{MBJK}\left(S_{t}^{P C A}\right)$ & 0.21 & 0.37 & 0.37 & 0.44 & 0.32 & 0.29 & 0.30 & 0.26 & 0.17 & 0.12 & 0.12 & 0.06 \\
\hline TSMOM & 0.00 & 0.14 & 0.05 & -0.01 & -0.03 & -0.04 & -0.09 & -0.11 & -0.13 & -0.12 & -0.13 & -0.12 \\
\hline \multicolumn{13}{|c|}{ Panel C: Fama-French 4-factor Regression } \\
\hline & \multicolumn{2}{|c|}{ Intercept } & \multicolumn{2}{|c|}{ RMRF } & \multicolumn{2}{|c|}{ SMB } & \multicolumn{2}{|c|}{ HML } & \multicolumn{2}{|r|}{ WML } & \multicolumn{2}{|c|}{$\operatorname{adj} . R^{2}$} \\
\hline$S_{t}^{P C A}$ & \multicolumn{2}{|c|}{$0.85 * *$} & \multicolumn{2}{|c|}{$0.47 * * *$} & \multicolumn{2}{|c|}{-0.09} & \multicolumn{2}{|c|}{$0.24 *$} & \multicolumn{2}{|r|}{-0.19} & \multicolumn{2}{|r|}{0.65} \\
\hline$t$-stat & \multicolumn{2}{|c|}{2.21} & \multicolumn{2}{|c|}{5.00} & \multicolumn{2}{|c|}{-1.01} & \multicolumn{2}{|c|}{1.91} & \multicolumn{2}{|r|}{-1.49} & \multirow{3}{*}{\multicolumn{2}{|c|}{0.63}} \\
\hline TSMOM & & 0.40 & & $4 * * *$ & & 0.11 & 0.3 & $* * *$ & & $38 * * *$ & & \\
\hline$t$-stat & & 1.04 & & 3.69 & & 0.77 & & 2.83 & & 2.71 & & \\
\hline
\end{tabular}




\section{Appendix A: Predictive Regression, Estimation Bias, and Monte Carlo Simulation}

Accessing the return predictability of one economic variable is not only an economic issue but also an econometric one. Even for a univariate predictive regression, the standard OLS method produces biased coefficients (the well-known Stambaugh (1999) small-sample bias), when the regressor is persistent and its innovations are correlated with those of the dependent variable. To illustrate this point, we follow the general setup in the econometrics literature by considering the following (single-regressor) predictive regression model.

$$
\begin{aligned}
& y_{t}=\alpha+\beta x_{t-1}+u_{t} \\
& x_{t}=\theta+\rho x_{t-1}+v_{t}
\end{aligned}
$$

where $y_{t}$ is the stock or portfolio returns (in excess of risk-free rate) at period $t, x_{t-1}$ is the lagged predictor variable which follows an AR(1) process as specified in Eq. [A.2], and the innovation terms $\left(u_{t}, v_{t}\right)$ follow a joint normal distribution with zero mean and a covariance matrix

$$
\left(\begin{array}{cc}
\sigma_{u}^{2} & \sigma_{u v} \\
\sigma_{u v} & \sigma_{v}^{2}
\end{array}\right) .
$$

The relationship between $u_{t}$ and $v_{t}$ can also be expressed in the following equation.

$$
u_{t}=\xi v_{t}+e_{t}
$$

where $\xi=\sigma_{u v} / \sigma_{v}^{2}$ and $e_{t}$ is the i.id. error term.

Given the above setup, Stambaugh (1999) provides an analytical expression for the bias of the OLS estimator, $\hat{\beta}$, which is exact for any given sample size $T$. (The bias in $\hat{\beta}$ depends on both $\xi$ and the estimation bias in the autoregressive estimator, $\hat{\rho}$.)

$$
\mathrm{E}(\hat{\beta})-\beta=\xi[\mathrm{E}(\hat{\rho})-\rho]
$$

Building on the work of Marriott and Pope (1954) on the bias in the estimation of the autocorrelation, Stambaugh (1999) further provides an approximation for the bias in $\hat{\beta}$.

$$
\mathrm{E}(\hat{\beta})-\beta=-\xi \frac{(1+3 \rho)}{T}+\mathrm{O}\left(\frac{1}{T^{2}}\right)
$$

As it stands, the magnitude of the bias is proportional to $\xi$ and the (true) autoregressive coefficient, $\rho$, but is inversely proportional to sample size $T$.

One caveat to be noted is that unlike many other predictive variables (such as dividend yields), the innovations of sentiment have a positive correlation with those of stock returns, that is, a positive $\xi$ in the case of stock return and investor sentiment in Eq. [A.4]. Given that the (true) autocorrelation coefficient $\rho$ is bounded in $(0,1)$ for a stationary autoregressive process, the $\hat{\beta}$ 
coefficient in Eq. [A.1] is bound to be downward biased (meaning that the OLS estimator is smaller than the true parameter, see Eq. [A.6]). The downward bias is more pronounced when the sample size is small. To sum up, empirical studies tend to be biased towards the finding of contrarian predictability of sentiment at short-horizons (weekly or monthly frequency), even if there exists no return predictability at all (or very small positive return predictability). To illustrate this point, we carried out simulations to provide additional insights on the potential adverse impact on the small-sample bias problem. Of course, the small-sample bias has made itself a hot topic in the econometric literature, as multiple bias-reduction techniques have been proposed in the literature (Amihud \& Hurvich 2004; Amihud et al. 2009; Chiquoine \& Hjalmarsson 2009; Zhu 2013).

We provide below two simulation cases whose parameters are designed to mirror our sample statistics. Estimation results of the standard OLS method and several bias-reduction techniques, including the univariate Augmented Regression Method (uARM) as in Amihud and Hurvich (2004), the multivariate Augmented Regression Method (mARM) of Amihud et al. (2009) and the Moving-block Jackknife (MBJK) method by Zhu (2013), are presented for comparison purpose.

We simulate stock market returns and investor sentiment data using Eq. [A.1] and [A.2], where the parameters $\alpha$ and $\theta$ are set as zero, the autoregressive root $\rho$ is set as 0.6597 , and the innovation terms $\left(u_{t}, v_{t}\right)$ follow a joint normal distribution with zero mean and a covariance matrix $\left(\begin{array}{ll}0.0066 & 0.0372 \\ 0.0372 & 0.5883\end{array}\right)$. The sample size is fixed at 202. These parameter values follow closely our sample characteristics. To illustrate the adverse impact due to finite-sample bias, we set the $\beta$ coefficient equal to 0 and 0.01 in case 1 and 2, respectively. Table A.1 presents the simulation results.

As is demonstrated by the simulation evidence in Table A.1, the slope coefficient of the predictive regression using the OLS method is downward biased in both simulation cases. Even if there is no real return predictability (as in case 1), the OLS method tends to find negative slope values, which might lead scholars to (erroneously) conclude that investor sentiment is a contrarian predictors at short horizons (e.g. weekly or monthly frequency). Even if sentiment is a momentum predictor (as in case 2), its economic relevance tends to be smaller as evaluated by the OLS method due to the downward bias. In case 2, it seems that the OLS bias in the slope coefficient amounts to $10 \%$ of the true parameter, which is not negligible in real applications. Table A.1 also offers a small-scale horserace on the competing method of bias reduction. In both 
cases, the mARM method tends to provide the best estimation results, as its bias is the smallest, while the variation of the slope coefficient is also among the smallest. The uARM method performs slightly worse than mARM in case 1, as it leads to larger bias in absolute terms. Although the MBJK method reduces the estimation bias quite satisfactorily, it produces larger estimation uncertainty as indicated by its inflated standard errors, which is also admitted in Zhu (2013). Overall, our simulation evidence favors the use of the mARM method in our empirical application of the article.

\section{Appendix B: Portfolio Implications: Asset Allocation Strategy}

Here we offer additional insights by using the conventional asset allocation strategy for a meanvariance investor (DeMiguel et al. 2009): The mean-variance investor dynamically allocates between the risky asset (market portfolio) and risk-free asset based on the one-period-ahead expected (excess) return generated by Eq. [4.4]. At the end of period $t$, the investor allocates $w_{t}$ of the portfolio to the market portfolio and the remaining $\left(1-w_{t}\right)$ of the portfolio to the risk-free asset. The equity proportion $w_{t}$ depends on two factors. First, it is the (expected) market price of risk, calculated as the ratio of forecasted excess return of the market portfolio $\left(E_{t}\left(R_{t+1}\right)\right)$ to its associated variance $\left(\operatorname{Var}_{t}\left(R_{t+1}\right)\right)$. The expected variance is measured with the five-year rolling window of monthly excess returns. Second, it is inversely related to the risk aversion coefficient, $\gamma$. The equity proportion is expressed in the following equation.

$$
w_{t}=\left(\frac{1}{\gamma}\right)\left(\frac{E_{t}\left(R_{t+1}\right)}{\operatorname{Var}_{t}\left(R_{t+1}\right)}\right)
$$

For realistic concerns, we place two boundary constraints on the portfolio weight on equities: The value of $w_{t}$ cannot be negative and its maximum is set at 1.5. These boundary restrictions correspond to the short-sales constraint and the leverage constraint, respectively. Both well reflect the real-world conditions in China's stock market. The realized excess return of the portfolio $R_{t+1}^{P}$ at period $t+1$ is then calculated as

$$
R_{t+1}^{P}=w_{t} R_{t+1}
$$

To evaluate the portfolio performance, we calculate the (out-of-sample) Sharpe ratio and the certainty equivalent return $(C E Q)$, respectively. 


$$
\begin{gathered}
\widehat{S R}_{P}=\frac{\hat{\mu}_{P}}{\hat{\sigma}_{P}} \\
\widehat{C E Q}_{P}=\hat{\mu}_{P}-\frac{\gamma}{2} \hat{\sigma}_{P}^{2}
\end{gathered}
$$

where $\hat{\mu}_{P}$ and $\hat{\sigma}_{P}$ denotes the mean and standard deviation of the portfolio excess returns, and $\gamma$ is the risk-aversion coefficient.

To gauge the economic value of the out-of-sample predictability enhanced by investor sentiment, we then compute the Sharpe ratio difference and the $C E Q$ gain between an investor who adopts the portfolio strategy based on predictive regression in Eq. [4.4] and another investor who uses the benchmark portfolio strategy with the historical average only. To assess the statistical significance of the Sharpe ratio difference, we perform the test of Jobson and Korkie (1981) corrected by Memmel (2003) (JKM-test hereafter). The null hypothesis of the JKM-test is that the Sharpe ratio difference of two competing strategies is indistinguishable from zero. Similarly, we evaluate the significance of the $C E Q$ gain by performing the test outlined in DeMiguel et al. (2009) (DGU-test hereafter). The null hypothesis of the DGU-test is that the CEQ gain is indistinguishable from zero between two competing strategies.

Table A.3 reports the asset allocation results based on the dynamic portfolio allocation strategy. Recall (from Section 3.3) that the (implied) risk aversion coefficient $(\gamma)$ of an average investor in China is only around 0.25 given the speculative nature of the market. Therefore, we consider three ad-hoc scenarios in which $\gamma$ equals $0.25,0.5$, and 1 , respectively. ${ }^{1}$ These ad-hoc values of $\gamma$ more or less correspond to an investor who has average, above-average, and extreme risk aversion in China (putting $100 \%, 50 \%$, and $25 \%$ of his or her wealth in the risky portfolio). Panel A of the table shows that the PCA sentiment index generates large economic gains for a meanvariance investor, which is consistent with the findings in Table 5. The CEQ gains range between $1.46 \%$ and $1.61 \%$ under the alternative estimation techniques, which are all statistically significant at the $10 \%$ or better levels in the baseline case. The Sharpe ratio of the testing portfolio is also significantly larger than that of the benchmark portfolio (which uses only

\footnotetext{
${ }^{1}$ We noted that the larger the value of the risk-aversion coefficient, the more frequent the investor tilts the portfolio towards the risk-free asset. In extreme cases, the investor keeps holding the risk-free asset for prolonged period of time, which makes the portfolio allocation strategy less meaningful. This is exactly the reason why we present the baseline case of $\gamma=0.25$, in which the agent has normal risk-aversion and is willing to hold the entire risky asset (after all, the market portfolio is held by the total economy). We thank an anonymous referee for bringing this to our attention.
} 
historical average as its return forecast) at the $10 \%$ or even finer significance level. The $C E Q$ gains range between $0.92 \%$ and $1.36 \%$ at the $10 \%$ significance level when the risk aversion coefficient is 0.50 . As the investor gets extremely risk averse $(\gamma=1.0)$ by penalizing more on the return variability, the $C E Q$ gains get smaller in magnitude. However, the Sharpe ratio remains significant and large in magnitude under all three scenarios. Specifically, the Sharpe ratio difference between the portfolio strategy based on return predictions from Eq. [4.4] and the benchmark portfolio strategy using only the historical average is statistically significant at the $10 \%$ or finer levels, irrespective the value of the risk-averse coefficient. We find very similar patterns of the portfolio allocation results based on the naïve sentiment index in Panel B of the table. Both the magnitude and statistical significance of the $C E Q$ gains and Sharpe ratios are very similar for the two sentiment indices. Panels C, D, and E present the asset allocation results based on the signals generated by the single-factor predictor model using BCI, IP, and PE respectively. We do find some evidence that BCI also delivers enhanced asset allocation results compared with the benchmark strategy with historical average. But, in general, these fundamentals offer less forecasting power as compared with sentiment indices.

Summarizing the table, we find consistent evidence that the improved forecasting ability with investor sentiment translates into economically relevant gains for an investor who uses predictive regressions, with or without bias-reduction techniques, to time the market. We also check the asset allocation implications based on forecasts generated by multivariate predictive regressions (which includes sentiment and other economic variables) to explore a larger set of price-related information. The forecast results are in general slightly better than the univariate case (untabulated).

\section{Appendix C: Robustness Checks on the Long-term Return Predictability}

For robustness purposes, we consider an alternative model specification for the multi-horizon predictive regression.

$$
R_{t+h}=\alpha+\beta \operatorname{sign}\left(S_{t}\right)+\psi^{\prime} Z_{t}+u_{t+h}
$$

where $R_{t+h}$ is the market excess return in the period $t+h, S_{t}$ is the $h$-period lagged predictor (sentiment proxy) measured at the end of period $t, \operatorname{sign}\left(S_{t}\right)$ is the sign of the sentiment proxy, 
which equals 1 when it is positive, and -1 otherwise. We also include a vector of conventional macro variables to control for the shifts in fundamentals. The additional control variables are business cycle indicator (BCI), industrial production (IP), and aggregated PE ratio (PE) similar to subsection 4.1.2. Again, we test the null hypothesis $\left(H_{0}: \beta=0\right)$ that investor sentiment has no predictive ability by evaluating the slope coefficient.

Figure A.2 plots the term structure of the return predictability under the alternative model specification. We find the term structure of the return predictability is very similar to that using the investor sentiment index directly as the predicting variable. Within the first year, sentiment serves mostly as a momentum signal, while over longer horizons it becomes a contrarian predictor. Overall, the similar pattern reinforces the robustness of our findings in the main text.

\section{Table A.1. Finite-sample Performance in Univariate Regressions}

The table reports the estimated slope coefficient $(\beta)$ in Eq. [A.1], denoted as Coef. and its standard error, denoted as S.E., using the simulated standard deviations based on 1500 realizations for two simulation cases. The estimation methods are ordinary least square method (OLS), the multivariate Augmented Regression Method (mARM), the univariate Augmented Regression Method (uARM), and the Moving-block Jackknife method (MBJK) with the length of the moving-block subsamples set as $0.3,0.5$, and 0.7 (of the total sample length) respectively.

In both cases, stock market returns and investor sentiment data are simulated with Eq. [A.1] and [A.2], where $\alpha=\theta=0, \rho=0.6597$, and the innovation terms $\left(u_{t}, v_{t}\right)$ follow a bivariate normal distribution with mean zero and a covariance matrix $\left(\begin{array}{ll}0.0066 & 0.0372 \\ 0.0372 & 0.5883\end{array}\right)$. The sample size is fixed at 202 . The $\beta$ coefficient equals to 0 and 0.01 in case 1 and 2, respectively. For each case, 1500 replications are performed.

\begin{tabular}{lrrrr}
\hline & Case 1: $\beta=0$ & \multicolumn{2}{c}{ Case 2: $\beta=0.01$} & S.E. \\
\hline OLS & Coef. & S.E. & Coef. & 0.0057 \\
mARM & -0.0012 & 0.0056 & 0.0091 & 0.0057 \\
uARM & -0.0002 & 0.0056 & 0.0100 & 0.0057 \\
MBJK_3 & -0.0003 & 0.0056 & 0.0100 & 0.0059 \\
MBJK_5 & -0.0003 & 0.0058 & 0.0101 & 0.0066 \\
MBJK_7 & -0.0004 & 0.0065 & 0.0101 & 0.0084 \\
\hline
\end{tabular}




\section{Table A.2. Statistics of Stock Exchanges}

\section{Panel A: Ranking of the major stock exchanges by the total value of market capitalization as of 31/12/2013}

\begin{tabular}{|c|c|c|c|c|c|c|}
\hline & & \# of & tocks & (1). Market Capitalization & (2). Trading Volume & \\
\hline & Exchange Name & Local & Foreign & (in USD million) & (in USD million) & $(2) /(1)$ \\
\hline 1 & NYSE & 1852 & 519 & $17,949,883.80$ & $13,700,450.50$ & $76.33 \%$ \\
\hline 2 & NASDAQ & 2328 & 309 & $6,084,969.70$ & $9,584,742.20$ & $157.52 \%$ \\
\hline 3 & Japan Exchange Group & 3408 & 11 & $4,543,169.10$ & $6,304,927.50$ & $138.78 \%$ \\
\hline 4 & London Stock Exchange & 2164 & 572 & $4,428,975.30$ & $3,050,891.50$ & $68.88 \%$ \\
\hline 5 & $\begin{array}{l}\text { Euronext } \\
\text { (Amsterdam, Brussel, Lisbon, Paris) }\end{array}$ & 935 & 127 & $3,583,899.70$ & $1,661,878.30$ & $46.37 \%$ \\
\hline 6 & HongKong Stock Exchange & 1553 & 90 & $3,100,777.20$ & $1,323,373.30$ & $42.68 \%$ \\
\hline 7 & Shanghai Stock Exchange & 953 & 0 & $2,496,989.90$ & $3,731,128.90$ & $149.43 \%$ \\
\hline 8 & TMX Group - Canada & 3810 & 76 & $2,113,821.80$ & $1,371,477.70$ & $64.88 \%$ \\
\hline 9 & Deutsche Börse & 639 & 81 & $1,936,106.30$ & $1,334,544.90$ & $68.93 \%$ \\
\hline 10 & SIX Swiss Exchange & 236 & 36 & $1,540,699.80$ & $676,957.70$ & $43.94 \%$ \\
\hline 11 & Shenzhen Stock Exchange & 1536 & 0 & $1,452,153.60$ & $3,858,509.00$ & $265.71 \%$ \\
\hline 12 & Australian Securities Exchange & 1951 & 104 & $1,365,958.10$ & $881,555.60$ & $64.54 \%$ \\
\hline
\end{tabular}

Panel B: Breakdown of the ownership structure and total trading volume for the Shanghai Stock Exchange as of 31/12/2013

\begin{tabular}{lrr} 
Individual Investors & Market Capitalization & Trading Volume \\
Legal Person & $21.78 \%$ & $82.24 \%$ \\
Financial Institutions: & $63.64 \%$ & $2.46 \%$ \\
$\quad$ - Investment Funds & $14.58 \%$ & $15.3 \%$ \\
\hline
\end{tabular}

Source: Statistics of the major exchanges are from the yearly reports of the World Federation of Exchanges (http://www.world-exchanges.org); Statistics of the breakdown data of Shanghai Stock Exchange are from Annual Fact Book issued by Shanghai Stock Exchange. Note: Trading volume is measured as the dollar trading volume of the entire year. Financial Institutions include brokerage and security firms, investment funds (mutual funds), pension funds, asset under management, and QFII (qualified foreign institutional investor). Legal Person includes all other companies, corporations, enterprises, departments, juridical association and agents. 


\section{Table A.3. Asset Allocation Results}

This table reports CEQ gains and Sharpe ratio for a mean-variance investor, who dynamically allocates between equities and the risk-free asset based on the forecasts from predictable variable(s) instead of historical average. The investor is assumed to have a risk aversion coefficient of $0.25,0.5$, and 1 , respectively. The portfolio weights (with boundary restrictions) are determined recursively by the forecast on equity returns, formed using OLS, mARM, uARM, and MBJK estimation methods. We evaluate whether the CEQ gain is significantly larger than zero based on asymptotic distributions according to DeMiguel et al. (2009). We also perform the one-sided JKM-test on whether the testing portfolio's Sharpe ratio is significantly larger than that of the benchmark portfolio using historical average. $*, * *$, and $* * *$ stand for significance at the $10 \%, 5 \%$ and $1 \%$ level. The out-of-sample period is from January 2007 to December 2013.

\begin{tabular}{|c|c|c|c|c|c|c|}
\hline \multirow[b]{2}{*}{ Method (Variables) } & \multicolumn{2}{|c|}{$\gamma=0.25$} & \multicolumn{2}{|c|}{$\gamma=0.5$} & \multicolumn{2}{|c|}{$\gamma=1.0$} \\
\hline & CEQ gain & Sharpe ratio & CEQ gain & Sharpe ratio & CEQ gain & Sharpe ratio \\
\hline \multicolumn{7}{|c|}{ Panel A: PCA sentiment index } \\
\hline $\operatorname{OLS}\left(S_{t}^{P C A}\right)$ & $0.0147 *$ & $0.08^{*}$ & $0.0118^{*}$ & $0.10 *$ & $0.0106^{*}$ & $0.13^{*}$ \\
\hline $\operatorname{mARM}\left(S_{t}^{P C A}\right)$ & $0.0161 * *$ & $0.10 * *$ & $0.0136^{*}$ & $0.13^{*}$ & $0.0115^{*}$ & $0.14 *$ \\
\hline $\mathrm{uARM}\left(S_{t}^{P C A}\right)$ & $0.0157 * *$ & $0.09^{* *}$ & $0.0134^{*}$ & $0.12 *$ & $0.0114 *$ & $0.14 *$ \\
\hline $\operatorname{MBJK}\left(S_{t}^{P C A}\right)$ & $0.0146^{*}$ & $0.08^{*}$ & 0.0092 & 0.07 & 0.0089 & 0.11 \\
\hline \multicolumn{7}{|c|}{ Panel B: Naïve sentiment index } \\
\hline OLS $\left(S_{t}^{\text {Naive }}\right)$ & $0.0149 * *$ & $0.08 * *$ & $0.0112 *$ & $0.10^{*}$ & $0.0103 *$ & $0.12 *$ \\
\hline $\operatorname{mARM}\left(S_{t}^{\text {Naive }}\right)$ & $0.0157 * *$ & $0.09 * *$ & $0.0128 *$ & $0.12 *$ & $0.0112^{*}$ & $0.14 *$ \\
\hline $\mathrm{uARM}\left(S_{t}^{\text {Naive }}\right)$ & $0.0155^{* *}$ & $0.09 * *$ & $0.0126^{*}$ & $0.11^{*}$ & $0.0111^{*}$ & $0.13^{*}$ \\
\hline $\operatorname{MBJK}\left(S_{t}^{\text {Naive }}\right)$ & $0.0147 *$ & $0.08^{*}$ & 0.0094 & 0.08 & 0.0085 & 0.10 \\
\hline \multicolumn{7}{|c|}{ Panel C: BCI } \\
\hline $\operatorname{OLS}\left(B C I_{t}\right)$ & $0.0129 * *$ & $0.06 * *$ & $0.0079 * *$ & $0.06 * *$ & $0.0043 * *$ & $0.05^{* * *}$ \\
\hline $\operatorname{mARM}\left(B C I_{t}\right)$ & $0.0108 * *$ & $0.04 * *$ & $0.0057 * *$ & $0.04 * *$ & 0.0028 & $0.04 * *$ \\
\hline $\mathrm{uARM}\left(B C I_{t}\right)$ & $0.0106 * *$ & $0.04 * *$ & $0.0054 * *$ & $0.03 * *$ & 0.0031 & $0.04 * *$ \\
\hline $\operatorname{MBJK}\left(B C I_{t}\right)$ & $0.0143 * * *$ & $0.07 * *$ & $0.0106 * * *$ & $0.09 * * *$ & $0.0066 * *$ & $0.08 * * *$ \\
\hline \multicolumn{7}{|c|}{ Panel D: IP } \\
\hline $\operatorname{OLS}\left(I P_{t}\right)$ & -0.0015 & -0.08 & -0.0026 & -0.05 & -0.0026 & -0.03 \\
\hline $\operatorname{mARM}\left(I P_{t}\right)$ & -0.0016 & -0.08 & -0.0025 & -0.05 & -0.0026 & -0.03 \\
\hline $\mathrm{uARM}\left(I P_{t}\right)$ & -0.0016 & -0.08 & -0.0025 & -0.05 & -0.0026 & -0.03 \\
\hline $\operatorname{MBJK}\left(I P_{t}\right)$ & 0.0016 & -0.03 & 0.0000 & -0.02 & -0.0007 & 0.00 \\
\hline \multicolumn{7}{|c|}{ Panel E: PE } \\
\hline $\operatorname{OLS}\left(P E_{t}\right)$ & -0.0025 & -0.06 & -0.0091 & -0.10 & -0.0094 & -0.14 \\
\hline $\mathrm{mARM}\left(P E_{t}\right)$ & $0.0134^{*}$ & $0.07 * *$ & $0.0083^{*}$ & $0.07 *$ & $0.0044 * *$ & $0.05^{*}$ \\
\hline $\mathrm{uARM}\left(P E_{t}\right)$ & 0.0035 & -0.03 & 0.0011 & -0.01 & 0.0007 & 0.00 \\
\hline $\operatorname{MBJK}\left(P E_{t}\right)$ & -0.0019 & -0.09 & -0.0055 & -0.12 & -0.0050 & -0.14 \\
\hline
\end{tabular}


Figure. A.1. Time-series Plots of Excess Market Returns, Investor Sentiment, Business Cycle Indicator and Industrial

\section{Production}
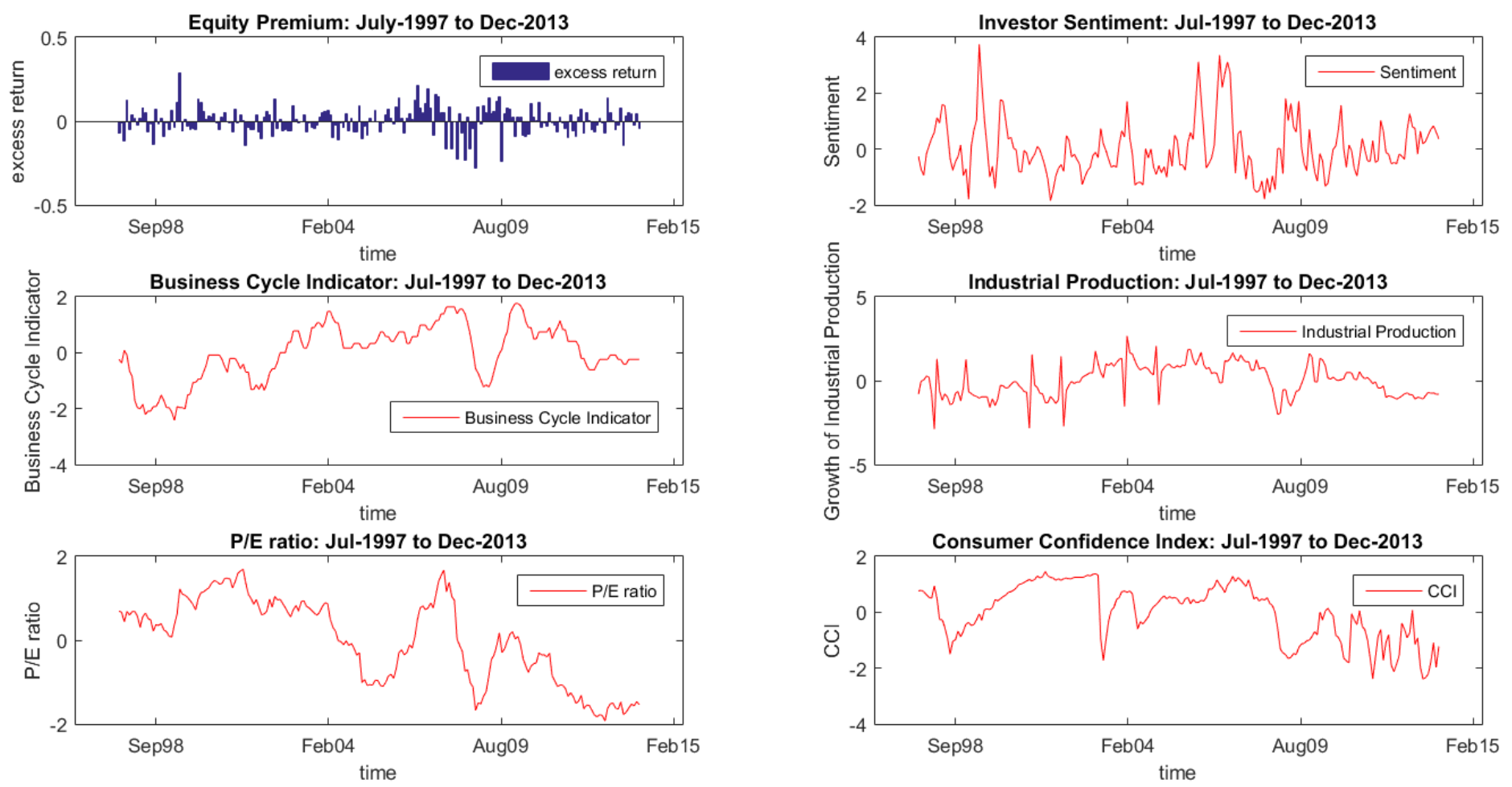

The figure includes the bar chart of the (monthly) market excess return (measured in decimals) and the time-series plots of the investor sentiment index obtained from the principal component analysis, the business cycle indicator, the growth of industry production, the value-weighted PE ratio, and the consumer confidence index. All the economic and financial variables (except the excess returns) are standardized to have mean zero and unit variance. The time-series plot covers the entire sample period from July 1997 to December 2013. 
Figure A.2: Multi-horizon Predictability Pattern under Alternative Model Specification
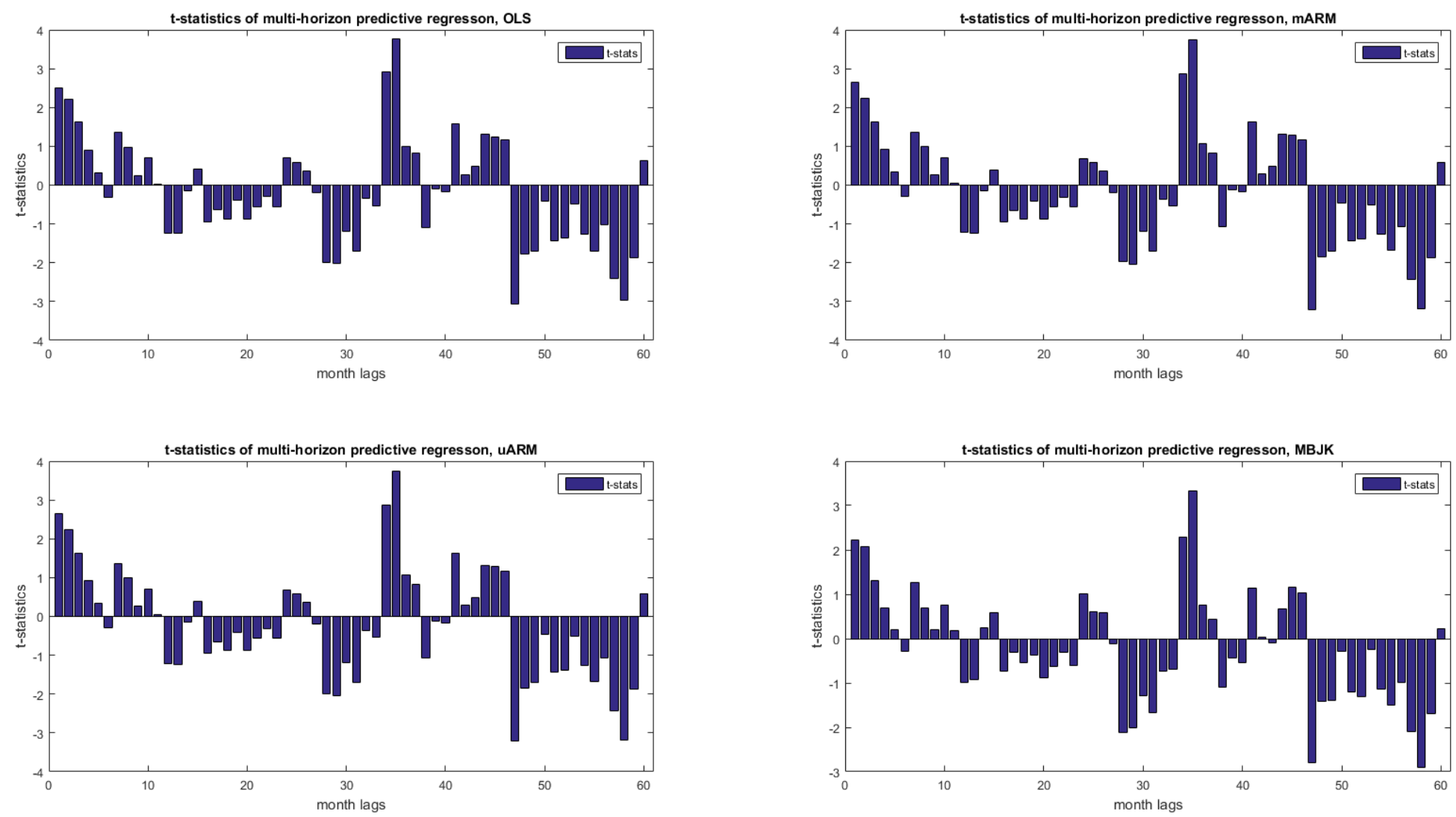

The figure depicts the $t$-statistics of the slope coefficients in the multi-horizon predictive regression under alternative model specification: $R_{t+h}=\alpha+$ $\beta \operatorname{sign}\left(S_{t}\right)+\psi^{\prime} Z_{t}+u_{t+h}$. Panel A to D represent the OLS, mARM, uARM, and MBJK methods, respectively. We regress the monthly excess return of the total market on the sign of the lagged sentiment index over various horizons. The horizons (month lags) vary from one month up to 60 months. The plot is obtained from the entire sample period from July 1997 to December 2013. 


\section{List of Reference}

Amihud, Y., Hurvich, C.M., 2004. Predictive Regressions: A Reduced-Bias Estimation Method. The Journal of Financial and Quantitative Analysis 39, 813-841

Amihud, Y., Hurvich, C.M., Wang, Y., 2009. Multiple-Predictor Regressions: Hypothesis Testing. Review of Financial Studies 22, 413-434

Baker, M., Stein, J.C., 2004. Market liquidity as a sentiment indicator. Journal of Financial Markets 7, 271-299

Baker, M., Wurgler, J., 2006. Investor sentiment and the cross-section of stock returns. The Journal of Finance 61, 1645-1680

Baker, M., Wurgler, J., 2007. Investor sentiment in the stock market. The Journal of Economic Perspectives 21, 129-151

Baker, M., Wurgler, J., Yuan, Y., 2012. Global, local, and contagious investor sentiment. Journal of Financial Economics 104, 272-287

Banerjee, A.V., 1992. A Simple Model of Herd Behavior. The Quarterly Journal of Economics $107,797-817$

Barberis, N., Shleifer, A., Vishny, R., 1998. A model of investor sentiment. Journal of Financial Economics 49, 307-343

Bodie, Z., Kane, A., Marcus, A.J., 2012. Essentials of Investments. McGraw-hill higher education

Boudoukh, J., Richardson, M., Whitelaw, R.F., 2008. The Myth of Long-Horizon Predictability. Review of Financial Studies 21, 1577-1605

Brown, G.W., Cliff, M.T., 2004. Investor sentiment and the near-term stock market. Journal of Empirical Finance 11, 1-27

Brown, G.W., Cliff, M.T., 2005. Investor Sentiment and Asset Valuation*. The Journal of Business 78, 405-440

Burdekin, R.C.K., Redfern, L., 2009. Sentiment effects on Chinese share prices and savings deposits: The post-2003 experience. China Economic Review 20, 246-261

Campbell, J.Y., Thompson, S.B., 2008. Predicting Excess Stock Returns Out of Sample: Can Anything Beat the Historical Average? Review of Financial Studies 21, 1509-1531

Chan, K., Menkveld, A.J., Yang, Z., 2008. Information Asymmetry and Asset Prices: Evidence from the China Foreign Share Discount. The Journal of Finance 63, 159-196

Chen, H., Chong, T.T.L., She, Y., 2014. A principal component approach to measuring investor sentiment in China. Quantitative Finance 14, 573-579

Chi, L., Zhuang, X., Song, D., 2012. Investor sentiment in the Chinese stock market: an empirical analysis. Applied Economics Letters 19, 345-348

Chiquoine, B., Hjalmarsson, E., 2009. Jackknifing stock return predictions. Journal of Empirical Finance 16, 793-803

Clark, T.E., West, K.D., 2007. Approximately normal tests for equal predictive accuracy in nested models. Journal of Econometrics 138, 291-311

De Long, J.B., Shleifer, A., Summers, L.H., Waldmann, R.J., 1990a. Noise trader risk in financial markets. Journal of political economy 98, 703-38

De Long, J.B., Shleifer, A., Summers, L.H., Waldmann, R.J., 1990b. Positive Feedback Investment Strategies and Destabilizing Rational Speculation. The Journal of Finance 45, 379-395 
DeMiguel, V., Garlappi, L., Uppal, R., 2009. Optimal versus naive diversification: How inefficient is the 1/N portfolio strategy? Review of Financial Studies 22, 1915-1953

Diebold, F.X., Mariano, R.S., 1995. Comparing Predictive Accuracy. Journal of Business \& Economic Statistics 13, 253-263

Fama, E.F., French, K.R., 1993. Common risk factors in the returns on stocks and bonds. Journal of Financial Economics 33, 3-56

Fama, E.F., French, K.R., 2012. Size, value, and momentum in international stock returns. Journal of Financial Economics 105, 457-472

Feng, L.E.I., Seasholes, M.S., 2004. Correlated trading and location. The Journal of Finance 59, 2117-2144

Ferson, W.E., Sarkissian, S., Simin, T.T., 2003. Spurious Regressions in Financial Economics? The Journal of Finance 58, 1393-1414

Fisher, K.L., Statman, M., 2000. Investor sentiment and stock returns. Financial Analysts Journal 56

Frazzini, A., Lamont, O.A., 2008. Dumb money: Mutual fund flows and the cross-section of stock returns. Journal of Financial Economics 88, 299-322

Frömmel, M., Han, X., 2014. Understanding the Controversy of Liquidity Beta. Available at SSRN

Georgopoulou, A., Wang, J., 2016. The Trend Is Your Friend: Time-Series Momentum Strategies across Equity and Commodity Markets. Review of Finance

Goyal, A., Welch, I., 2008. A Comprehensive Look at The Empirical Performance of Equity Premium Prediction. Review of Financial Studies 21, 1455-1508

Huang, D., Jiang, F., Tu, J., Zhou, G., 2014. Investor Sentiment Aligned: A Powerful Predictor of Stock Returns. Review of Financial Studies

Indro, D.C., 2004. Does mutual fund flow reflect investor sentiment? The Journal of Behavioral Finance 5, 105-115

Jegadeesh, N., Titman, S., 1993. Returns to Buying Winners and Selling Losers: Implications for Stock Market Efficiency. The Journal of Finance 48, 65-91

Jobson, J.D., Korkie, B.M., 1981. Performance Hypothesis Testing with the Sharpe and Treynor Measures. The Journal of Finance 36, 889-908

Kim, A.Y., Tse, Y., Wald, J.K., 2016. Time series momentum and volatility scaling. Journal of Financial Markets 30, 103-124

Kling, G., Gao, L., 2008. Chinese institutional investors' sentiment. Journal of International Financial Markets, Institutions and Money 18, 374-387

Kumar, A., Lee, C.M.C., 2006. Retail investor sentiment and return comovements. The Journal of Finance 61, 2451-2486

Lee, C.M.C., Shleifer, A., Thaler, R.H., 1991. Investor Sentiment and the Closed-End Fund Puzzle. The Journal of Finance 46, 75-109

Lemmon, M., Portniaguina, E., 2006. Consumer Confidence and Asset Prices: Some Empirical Evidence. Review of Financial Studies 19, 1499-1529

Levine, A., Pedersen, L.H., 2016. Which Trend Is Your Friend? Financial Analysts Journal 72, 51-66

Lo, A., MacKinlay, A., 1990. Data-snooping biases in tests of financial asset pricing models. Review of Financial Studies 3, 431-467

Marriott, F.H.C., Pope, J.A., 1954. Bias in the Estimation of Autocorrelations. Biometrika 41, 390-402 
Mei, J., Scheinkman, J.A., Xiong, W., 2009. Speculative trading and stock prices: Evidence from Chinese AB share premia. Annals of Economics and Finance 10, 225-255

Memmel, C., 2003. Performance hypothesis testing with the Sharpe ratio. Finance Letters 1

Moskowitz, T.J., Ooi, Y.H., Pedersen, L.H., 2012. Time series momentum. Journal of Financial Economics 104, 228-250

Nicholls, D.F., Pope, A.L., 1988. Bias in the Estimation Of Multivariate Autoregressions. Australian Journal of Statistics 30A, 296-309

Schmeling, M., 2007. Institutional and individual sentiment: Smart money and noise trader risk? International Journal of Forecasting 23, 127-145

Schmeling, M., 2009. Investor sentiment and stock returns: Some international evidence. Journal of Empirical Finance 16, 394-408

Shleifer, A., Summers, L.H., 1990. The Noise Trader Approach to Finance. The Journal of Economic Perspectives 4, 19-33

Stambaugh, R.F., 1999. Predictive regressions. Journal of Financial Economics 54, 375-421

Stambaugh, R.F., Yu, J., Yuan, Y., 2012. The short of it: Investor sentiment and anomalies. Journal of Financial Economics 104, 288-302

Tian, L., 2011. Regulatory underpricing: Determinants of Chinese extreme IPO returns. Journal of Empirical Finance 18, 78-90

Verma, R., Soydemir, G., 2009. The impact of individual and institutional investor sentiment on the market price of risk. The Quarterly Review of Economics and Finance 49, 1129-1145

Warther, V.A., 1995. Aggregate mutual fund flows and security returns. Journal of Financial Economics 39, 209-235

Zhu, M., 2013. Jackknife for Bias Reduction in Predictive Regressions. Journal of Financial Econometrics 11, 193-220 